\title{
Sex differences in cancer mechanisms
}

\author{
Joshua B. Rubin ${ }^{1,2^{*}}$, Joseph S. Lagas $^{1 \dagger}$, Lauren Broestl ${ }^{1 \dagger}$, Jasmin Sponagel ${ }^{1 \dagger}$, Nathan Rockwell ${ }^{1 \dagger}$, Gina Rhee ${ }^{\text {updates }}$ \\ Sarah F. Rosen ${ }^{3+}$, Si Chen ${ }^{4 \dagger}$, Robyn S. Klein ${ }^{2,3}$, Princess Imoukhuede ${ }^{4}$ and Jingqin Luo ${ }^{5 \dagger}$
}

\begin{abstract}
We now know that cancer is many different diseases, with great variation even within a single histological subtype. With the current emphasis on developing personalized approaches to cancer treatment, it is astonishing that we have not yet systematically incorporated the biology of sex differences into our paradigms for laboratory and clinical cancer research. While some sex differences in cancer arise through the actions of circulating sex hormones, other sex differences are independent of estrogen, testosterone, or progesterone levels. Instead, these differences are the result of sexual differentiation, a process that involves genetic and epigenetic mechanisms, in addition to acute sex hormone actions. Sexual differentiation begins with fertilization and continues beyond menopause. It affects virtually every body system, resulting in marked sex differences in such areas as growth, lifespan, metabolism, and immunity, all of which can impact on cancer progression, treatment response, and survival. These organismal level differences have correlates at the cellular level, and thus, males and females can fundamentally differ in their protections and vulnerabilities to cancer, from cellular transformation through all stages of progression, spread, and response to treatment. Our goal in this review is to cover some of the robust sex differences that exist in core cancer pathways and to make the case for inclusion of sex as a biological variable in all laboratory and clinical cancer research. We finish with a discussion of lab- and clinic-based experimental design that should be used when testing whether sex matters and the appropriate statistical models to apply in data analysis for rigorous evaluations of potential sex effects. It is our goal to facilitate the evaluation of sex differences in cancer in order to improve outcomes for all patients.
\end{abstract}

Keywords: Sex differences, Cancer, Epigenetics, Senescence, Immunity, Metabolism, p53, Tumor Suppressor, Angiogenesis

\section{Overview of sex differences in cancer}

Sex differences are evident in tumor incidence and mortality throughout the world, across a wide age range, and many different cancer types. Mo,st cancers with a clear sex difference affect males more than females, with incidence rates ranging from 1.26:1 to 4.86:1 (Table 1). These male predominant cancers include hematological

\footnotetext{
*Correspondence: Rubin_j@wustl.edu

† Joseph S. Lagas, Lauren Broestl, Jasmin Sponagel, Nathan Rockwell, Gina Rhee, Sarah F. Rosen, Si Chen and Jingqin Luo contributed equally to this work.

'Department of Pediatrics, Washington University School of Medicine, 660 South Euclid Avenue, St Louis, MO 63110, USA

${ }^{2}$ Department of Neuroscience, Washington University School of Medicine, 660 South Euclid Avenue, St Louis, MO 63110, USA

Full list of author information is available at the end of the article
}

malignancies, as well as cancers of the bladder, colon, skin, liver, and brain [1,2]. Males not only develop cancer more often but are also more likely to die from their disease [3-5]. To date, sex differences have also been demonstrated in rates and patterns of metastasis, expression of prognostic biomarkers, and response to different types of therapies in several different cancer types [6-8]. Despite this overwhelming evidence, sex differences have not been consistently considered when studying cancer, designing therapies, or constructing clinical trials. In part, this is driven by incomplete recognition of the varied mechanisms that contribute to sexual differentiation and an overemphasis on the role that circulating sex hormones plays in mediating sex differences in cancer.

(c) The Author(s). 2020 Open Access This article is licensed under a Creative Commons Attribution 4.0 International License, which permits use, sharing, adaptation, distribution and reproduction in any medium or format, as long as you give appropriate credit to the original author(s) and the source, provide a link to the Creative Commons licence, and indicate if changes were made. The images or other third party material in this article are included in the article's Creative Commons licence, unless indicated otherwise in a credit line to the material. If material is not included in the article's Creative Commons licence and your intended use is not permitted by statutory regulation or exceeds the permitted use, you will need to obtain permission directly from the copyright holder. To view a copy of this licence, visit http://creativecommons.org/licenses/by/4.0/. The Creative Commons Public Domain Dedication waiver (http://creativecommons.org/publicdomain/zero/1.0/) applies to the data made available in this article, unless otherwise stated in a credit line to the data. 
Table 1 Cancers with a clear sex disparity in age-adjusted incidence rates per 100,000 according to SEER explorer incidence data

\begin{tabular}{|c|c|c|c|}
\hline Cancer type & Male average incidence rates & Female average incidence rates & Male:female incidence ratio \\
\hline Oropharynx and tonsil & 4.18 & 0.86 & 4.86 \\
\hline Larynx & 5.2 & 1.1 & 4.73 \\
\hline Esophagus & 7.34 & 1.74 & 4.22 \\
\hline Urinary Bladder & 35.24 & 8.74 & 4.03 \\
\hline Mesothelioma & 1.58 & 0.4 & 3.95 \\
\hline Lip & 1.02 & 0.32 & 3.19 \\
\hline Liver and intrahepatic bile duct & 13.58 & 4.72 & 2.88 \\
\hline Tongue & 5.22 & 1.92 & 2.72 \\
\hline Oral cavity and pharynx & 17.02 & 6.38 & 2.67 \\
\hline Floor of mouth & 0.68 & 0.3 & 2.27 \\
\hline Kidney and renal pelvis & 22.16 & 10.92 & 2.03 \\
\hline Myelodysplastic syndromes & 6.2 & 3.26 & 1.9 \\
\hline Stomach & 10 & 5.36 & 1.87 \\
\hline Salivary gland & 1.7 & 1.02 & 1.67 \\
\hline Leukemia & 18.06 & 10.9 & 1.66 \\
\hline Melanoma of the skin & 28.78 & 17.46 & 1.65 \\
\hline Myeloma & 8.7 & 5.58 & 1.56 \\
\hline Non-Hodgkin lymphoma & 23.9 & 16.22 & 1.47 \\
\hline Gum and other mouth & 1.84 & 1.28 & 1.44 \\
\hline Soft tissue including heart & 4.14 & 2.92 & 1.42 \\
\hline Brain and nervous system & 7.52 & 5.36 & 1.4 \\
\hline Small intestine & 2.74 & 2.06 & 1.33 \\
\hline Eye and orbit & 1.02 & 0.78 & 1.31 \\
\hline Colon and rectum & 44.28 & 33.98 & 1.3 \\
\hline Lung and bronchus & 63.08 & 48.94 & 1.29 \\
\hline Pancreas & 14.66 & 11.48 & 1.28 \\
\hline Hodgkin lymphoma & 3 & 2.38 & 1.26 \\
\hline Anorectal & 1.56 & 2.22 & 0.7 \\
\hline Gallbladder & 0.9 & 1.5 & 0.6 \\
\hline Thyroid & 8.04 & 23.26 & 0.35 \\
\hline Breast & 1.24 & 127.5 & 0.01 \\
\hline
\end{tabular}

Incidence rates were calculated by averaging age-adjusted incidence rates per 100,000 from the last 5 years (2012-2016). Male:female ratio was calculated by dividing the male incidence rate by the female incidence rate, both shown in the table. The geometric mean of the male/female incidence ratio is 1.5

Circulating estrogen, progesterone, and testosterone, undoubtedly, contribute to the genesis and progression of some cancers. Breast and prostate cancer, for example, clearly respond strongly to circulating sex hormones [9-11]. Additionally, estrogen has been shown to be antitumorigenic for liver and colon cancer (which show a male predominance), and pro-tumorigenic for meningiomas and thyroid cancer (which show a female predominance). However, the molecular basis for the sex disparity in most cancers is still undefined [12-42]. For most cancer types, the magnitude of sex differences in incidence and severity do not parallel the age-dependent changes in circulating sex hormone abundance [36, 43]. Thus, circulating sex hormone actions cannot account for all sex differences in cancer, and acute hormone-independent cancer mechanisms remain to be fully determined.

Sex differences in cancer as well as in normal physiology, arise through sexual differentiation, a process involving genetics and epigenetics, in addition to acute sex hormone actions. Consequently, males and females differ in their rates of growth [44], myelination [45], immunity $[46,47]$, cardiovascular function [48], systemic metabolism [49], aging, and wound healing [50]. In this light, it should come as no surprise that sexual differentiation 
affects cancer incidence, response to treatment, and survival.

In this review, we will focus on specific cancer core mechanisms to illustrate how sexual dimorphisms in basic biological functions influence cancer biology, and might impact response to treatment. In some instances, we will focus on brain tumors for the following reasons: The geometric mean value for the sex differences ratio $(\mathrm{M} / \mathrm{F})$ in cancer incidence is approximately 1.5:1 (Table 1 ). The bias in glioblastoma (GBM) incidence is approximately 1.6:1 [51]. We expect that if there are adaptations to make in our science to best incorporate common mechanisms underlying sex differences in cancer, they will be most easily identified in a cancer like GBM, that occurs with a mean sex bias in incidence and for which there are data that span the scales of oncology research from the cellular to the patient level $[21,35,52-59]$. We conclude with a discussion of the rigorous statistical approaches for studying sex effects in the laboratory and the clinic (Table 2).

\section{Epigenetics}

\section{Epigenetics and cancer}

Over the past two decades, epigenetic dysregulation has emerged as a critical mechanism of cancer initiation and adaptation. We now recognize that essentially all cancer hallmarks that can be acquired through genetic mutation can similarly be achieved through epigenetic mechanisms. This can involve aberrant activation or silencing of specific loci, or global remodeling of the epigenetic landscape. Genes encoding epigenetic readers, writers, and erasers, as well as histone proteins themselves, are frequently mutated in human tumors [60-64], drawing a direct link between epigenetic dysregulation and tumorigenesis. Cellular differentiation is a process encoded by progressive layers of epigenetic restriction [65], and disruption of the normal epigenetic landscape can enable cancer cells to reactivate developmental programs and acquire features resembling stem cells [66, 67]. Epigenetic mechanisms also contribute to intra-tumor heterogeneity and therapeutic resistance [68-70]. Thus, targeting tumor epigenetics may be a strategy for improving treatment response [68, 71-73]. In this section, we will review the evidence that the epigenetic landscape of male and female cells differs, that this is a critical mechanism by which sexual dimorphism is established, and that this fundamental divergence in male and female biology, present in every cell of the body, has important implications for cancer risk and treatment.

\section{Sex differences in epigenetics}

Numerous studies have identified consistent sex differences in the epigenetic landscape in multiple tissues, spanning all ages, and across species. The most extensively profiled sexually dimorphic epigenetic mark is
Table 2 Content outline

1. Overview of sex differences in cancer

Table 1 Cancers with a clear sex disparity in age-adjusted incidence rates per 100,000 according to SEER explorer incidence data

2. Epigenetics

2.1: Epigenetics and cancer

2.2: Sex differences in epigenetics

2.3: Implications for targeting epigenetics

Fig. 1 Sex-specific epigenetic programming may contribute to differential barriers to tumorigenesis in males and females

3. Metabolism

3.1: Metabolism and cancer

3.2: Sex differences in metabolism

3.3: Implications for targeting metabolism

Fig. 2 Sex differences in metabolic pathways may contribute to sex differences in cancer development

4. $p 53$

4.1: $p 53$ and cancer

4.2 Sex differences in $\mathrm{p} 53$

4.3: Implications for targeting p53

5. Cellular senescence

5.1: Senescence and cancer

5.2: Sex differences in senescence

5.3: Implications for targeting senescence

Fig. 3 Sex differences in senescence and SASP may contribute to the increasing sex disparity in cancer incidence with age

6. Immunity

6.1: The immune system in cancer

6.2: Sex differences in the immune system

6.3: Implications for immunotherapy

Fig. 4 Sex differences in immune cells affecting cancer development

7. Angiogenesis

7.1: Angiogenesis and cancer

7.2: Sex differences in angiogenesis

7.3: Implications for targeting tumor angiogenesis

Fig. 5 Sex differences in endothelial cells, endothelial progenitor cells, circulating angiogenic factors, and sex hormones contribute to sex differences in tumor angiogenesis

8. Statistical considerations

Fig. 6 Visualizing statistical interaction

9. Perspectives and significance

DNA methylation. Sex-specific methylation patterns have been observed in blood [74-77], placenta [78], liver [79-82], pancreas [83], muscle [84], heart [81], and brain [81, 85-89]. Sex differences in histone modifications have also been described, although thus far only in mouse brain $[90,91]$. Since the majority of mechanistic studies on epigenetics and sexual differentiation have 
been performed in the brain, this will be our focus here; however, since sex differences in epigenetics are found throughout the body, it is likely that many of these mechanisms will apply to tissues more broadly.

Sexual dimorphism in the brain has been recognized since the 1950s and is understood to be largely determined by exposure to gonadal hormones during a critical window of in utero development. Early studies in rodents found that an injection of testosterone administered in utero, or during the perinatal period, results in permanent masculinization of adult behavior in females [92, 93], and evidence that this model also applies to humans is supported by case studies of disorders of sex development $[94,95]$. The finding that testosterone exposure resulted in a long-lasting and stable patterning of sexual differentiation led to the hypothesis that epigenetic programming may underlie sex differences, and a number of studies in the past decade have provided mechanistic evidence for this theory.

Neonatal female rats have higher levels of the DNA methyltransferase Dnmt3a in the amygdala compared to males, and treating with testosterone significantly decreased this expression [96], indicating it is an important regulator of DNA methylation. In agreement with this, neonatal female rats also had higher methylation levels in the promoter of the estrogen receptor (ER)- $\alpha$ gene, compared to both males and females masculinized by gonadal hormone exposure [97]. Genome wide methylation surveys of the striatum and bed nucleus of the stria terminalis/preoptic area (BNST/POA), a known sexually dimorphic brain region, showed that female mice treated with testosterone on postnatal day 0 had an altered methylation pattern that resembled that of males, when they were profiled at postnatal day 60 [85]. In 2015, Nugent et al. demonstrated that gonadal steroid exposure during development decreased the activity of DNA methyltransferases (DNMTs) in the POA, lowering DNA methylation levels in females to levels equivalent to males. Knocking out Dnmt3A or pharmacologically inhibiting Dnmts masculinized sexual behavior in females, even when treatment was given outside the critical window [98]. Additionally, treatment with DNMT inhibitors reverses some anatomical and functional sex differences in the POA [99]. Together, these studies suggest that DNA methylation actively suppresses masculinizing genes in order to maintain brain feminization, and that this depends on levels of gonadal hormones during development. Intriguingly, when embryonic neural stem cells (eNSCs) were treated with testosterone in vitro, it resulted in a global decrease in DNA methylation in both XX and XY cells [100]. A similar result was reported for DNA methylation in liver, in which males were hypomethylated compared to females, and this was dependent on testosterone exposure [82]. These studies indicate that sexual differentiation involves sex-specific regulation of DNA methylation.

Differences in male and female methylation patterns may have important implications for cancer development. One epigenetic change recognized in many cancers, though with some exceptions (notably isocitrate dehydrogenase (IDH)-mutant gliomas [101]), is a propensity for global hypomethylation [102, 103]. DNA hypomethylation is associated with increased cancer malignancy, and mutations in Dnmts are cancer promoting in multiple mouse models. Broad regions of hypomethylation (both DNA and histone) are believed to contribute to dedifferentiation and the cancer stemcelllike state, and to increase epigenetic plasticity [62]. Another scenario in which cells reacquire a stem cell phenotype is through reprogramming to induced pluripotent stem cells (iPSCs), a process that has some parallels to cancer evolution [67]. During reprogramming, DNA methylation marks associated with cell typespecific differentiation are erased, and reprogramming efficiency can be enhanced by the inhibition of DNMTs [104]. Thus, male- and female-specific methylation patterns could influence the ability of cancer cells to adopt a stem cell-like phenotype.

Sex differences in histone modifications also underlie sexual differentiation of the brain. Matsuda et al. found that there were sex differences in histone acetylation levels of the ER $\alpha$ and aromatase promoters, two genes essential for masculinization, during the critical period. Inhibiting histone deacetylases (HDACs) at postnatal day $0 / 1$ resulted in decreased male sexual behavior, suggesting that histone deacetylation is required for proper sexual differentiation [105]. HDAC inhibitors also eliminated anatomical sex differences in the BNST [106]. Treating eNSCs with testosterone in vitro led to a global increase in histone $\mathrm{H} 3$ acetylation in daughter lineages, supporting the hypothesis that gonadal hormones can exert stable effects on the genome via histone modifications [100]. Of note, upregulated genes in both $\mathrm{XX}$ and $\mathrm{XY}$ eNSCs treated with testosterone were highly enriched for pathways involved in nucleosome organization, nucleosome assembly, and chromatin assembly, suggesting that testosterone-mediated transcriptional changes could drive downstream epigenetic reorganization [100]. Together, these studies provide strong evidence that gonadal steroid exposure during the critical period mediates sexual differentiation of the brain via epigenetic mechanisms.

Gonadal hormone exposure is not the only mechanism by which epigenetics can diverge in males and females. In preimplantation embryos, hundreds to thousands of genes differ in expression between the sexes [107-110], despite the fact that gonadal differentiation has yet to occur. The basis of sexual dimorphism in these early 
embryos is the unique complement of sex chromosomes in male (XY) and female (XX) cells. One of the most striking differences in male and female epigenetics is the inactivation of the additional X-chromosome in female cells. This inactivation is orchestrated by the long non-coding RNA (lncRNA) XIST, which mediates chromosome-wide silencing through histone deacetylation and subsequent enrichment of repressive chromatin marks [111]. This results in a dense, highly stable, heterochromatic region unique to female cells. Removal of these heterochromatic marks, and reactivation of the $\mathrm{X}$-chromosome, is one of the steps that takes place during reprogramming to iPSCs in mouse cells [112], though the status of the inactive $\mathrm{X}$ is more complicated in human iPSCs [113, 114]. As mentioned above, reprogramming to iPSCs has some parallels to cancer dedifferentiation. Intriguingly, generation of iPSCs from mouse embryonic fibroblasts is more efficient when using male cells than when using female cells, and it is speculated that this may be due to an X-chromosome reactivation barrier [115]. Furthermore, there is evidence that $\mathrm{X}$ inactivation is lost in some female cancers, through either mitotic errors or epigenetic dysregulation and reactivation $[116,117]$. Whether $\mathrm{X}$-chromosome reactivation dynamics contribute to female protection in cancer has not been investigated.

$X I S T$ and other lncRNAs of the $\mathrm{X}$ inactivation center (XIC) may have more direct roles in tumor risk as well. XIST appears to be both tumor-promoting and tumorsuppressive, depending on cancer type and context [118]. Surprisingly, two meta-analyses of XIST in cancer identified no association between XIST and sex/gender, but did find that high levels were associated with poor overall survival $[119,120]$. Although XIST is not normally expressed in $\mathrm{XY}$ cells, these studies suggest that aberrant regulation of this IncRNA can occur in both male and female tumors. FTX, another lncRNA involved in $\mathrm{X}$ inactivation, has been identified as a putative tumor suppressor in hepatocellular carcinoma (HCC). It is expressed at higher levels in tumors from female patients, positively correlates with survival, and inhibits HCC cell proliferation and invasion [121]. Additional XIC lncRNAs, such as JPX [122] and TSIX [123] may also have roles in cancer initiation and progression. Because expression of IncRNAs involved in $\mathrm{X}$ inactivation differs in normal $\mathrm{XX}$ and $\mathrm{XY}$ cells, this could contribute to sex differences in cancer risk. In addition to the lncRNAs of the XIC, multiple other lncRNAs, located throughout the genome, have been identified as sexbiased in expression [110, 124, 125]. Functions of lncRNAs include modifying chromatin state and regulating gene expression [126]; thus, differences in even a small number of lncRNAs could have wide ranging effects. As with protein-coding genes, lncRNAs can act as either tumor suppressors or tumor promoters, and are now recognized to be frequently dysregulated in cancer [127-131].

LncRNAs also have important roles in regulating imprinting. In genomic imprinting, a gene is preferentially expressed from either the maternal or paternal allele [132]. Since both male and female embryos inherit a full set of autosomes from their mother and father, the majority of imprinted regions do not differ between the sexes. However, there is evidence that, at least in brain, the sex of the offspring can affect imprinting, with some autosomal loci imprinted in one sex but not the other [110, 133]. The greatest differences in imprinting emerge from the X-chromosome. Male embryos inherit only the maternal $\mathrm{X}$, while female embryos inherit both a maternal and paternal X [132]. Differences in the phenotype of XO girls who inherit a paternal $\left(\mathrm{X}_{\mathrm{p}}\right)$ vs. a maternal $\left(\mathrm{X}_{\mathrm{m}}\right) \mathrm{X}$ chromosome, suggest that $\mathrm{X}$-chromosome imprinting does impact development, particularly in the brain [132, 134]. Intriguingly, one study found a trend towards increased brain volume in $\mathrm{X}_{\mathrm{m}} \mathrm{O}$ girls, compared to $\mathrm{X}_{\mathrm{p}} \mathrm{O}$ girls [134], suggesting potential roles of $\mathrm{X}$ imprinted genes on regulating growth. However, no studies have examined if cancer rates differ in $\mathrm{X}_{\mathrm{m}} \mathrm{O}$ or $\mathrm{X}_{\mathrm{p}} \mathrm{O}$ women, or if imprinted $\mathrm{X}$ genes contribute to sex differences in cancer risk.

Prior to X-chromosome inactivation (XCI), female embryos are exposed to a double dose of X-chromosome genes, while male embryos get a single $\mathrm{X}$ dose plus a much smaller number of Y-chromosome genes. However, even after X-chromosome inactivation, a percentage of genes on the $\mathrm{X}(15 \%$ in humans [135] and $3 \%$ in mouse [136]) escape inactivation, and are expressed at higher levels in females. Differences in $\mathrm{X}$ and $\mathrm{Y}$ gene expression appear to exert broad downstream effects, resulting in genome-wide transcriptional differences [100, 110, 137]. One mechanism by which sex chromosomes may exert broad regulatory effects is through epigenetic regulation. A number of important epigenetic modifiers are located on the X-chromosome [138], including lysine demethylases KDM5C and KDM6A (UTX). Both KDM5C and KDM6A are known to escape $\mathrm{X}$ chromosome inactivation, are expressed at higher levels in females, and do not appear to be fully compensated by their Y-chromosome paralogues KDM5D and UTY [139-141]. $K D M 6 A$ and $K D M 5 C$ are two of several putative tumor suppressors on the X-chromosome proposed to contribute to decreased cancer risk in females. These genes, along with $A T R X, D D X 3 X, C N K S R 2$, and MAGEC3 are more frequently mutated in male tumors [142], presumably because females have a second copy to compensate for any loss of function mutations via XCI escape. KDM6A in particular has been found to contribute to sex differences in bladder cancer, where it acts as a tumor suppressor in XX individuals [143]. It has also been identified as a tumor suppressor in B cell lymphoma [144], $\mathrm{T}$ cell acute lymphoblastic leukemia [145], and pancreatic cancer [146]. In addition to 
differences in the expression levels of protein-coding genes located on the sex chromosomes, IncRNAs [147] and microRNAs (miRNAs) can also escape X inactivation and differ in expression between the sexes. The X-chromosome contains an unusually high number of miRNAs, 118 compared to an average of 40-50 on the autosomes [148]. These miRNAs are regulators of a diverse array of processes, many of which are relevant to cancer [131, 149, 150].

Finally, in addition to both gonadal hormone and sex chromosome effects, other complex mechanisms may contribute to sex differences in epigenetics. For example, the enzymes that catalyze chromatin modifications require metabolites as both cofactors and substrates [151, 152], and to add further complexity, some metabolites can act as inhibitors of epigenetic enzymes; the ketone body $d-\beta$ hydroxybutyrate is an HDAC inhibitor [153], and the oncometabolite 2-hydroxyglutarate (2-HG) acts as a competitive antagonist to $\alpha$-KG-dependent demethylases [154]. As detailed below, metabolism differs fundamentally in males and females, providing another potential source for epigenetic sex differences.

Together, these varied mechanisms lead to fundamental differences in the epigenomes of male and female cells that likely contribute to sex differences in the cell intrinsic barrier to malignant transformation (Fig. 1).

\section{Implications for targeting epigenetics}

Given the central role of epigenetic dysregulation in cancer initiation, progression, and therapeutic resistance, it is no surprise that drugs targeting epigenetic regulators are emerging as promising cancer therapeutics [73]. There is already evidence that treating with DNMT inhibitors can affect sexually dimorphic epigenetic marks, even when given after sexual differentiation is complete [98], and a recent study showed that combination treatment with an EZH2 inhibitor and HDAC inhibitor at sub-therapeutic levels disrupted X-chromosome inactivation in normal human female fibroblasts [155]. Furthermore, how sex differences in epigenetics interact with epigenetic dysregulation in cancer is currently not well understood. Thus, it will be critical to evaluate clinical efficacy and side effects of epigenetic therapeutics in both sexes separately.

\section{Metabolism \\ Metabolism and cancer}

Sex differences in metabolism have been extensively reported during development, adulthood, and in certain diseases, such as obesity and diabetes. Even though metabolic reprogramming is an essential process in cancer, sex differences in cancer metabolism have not

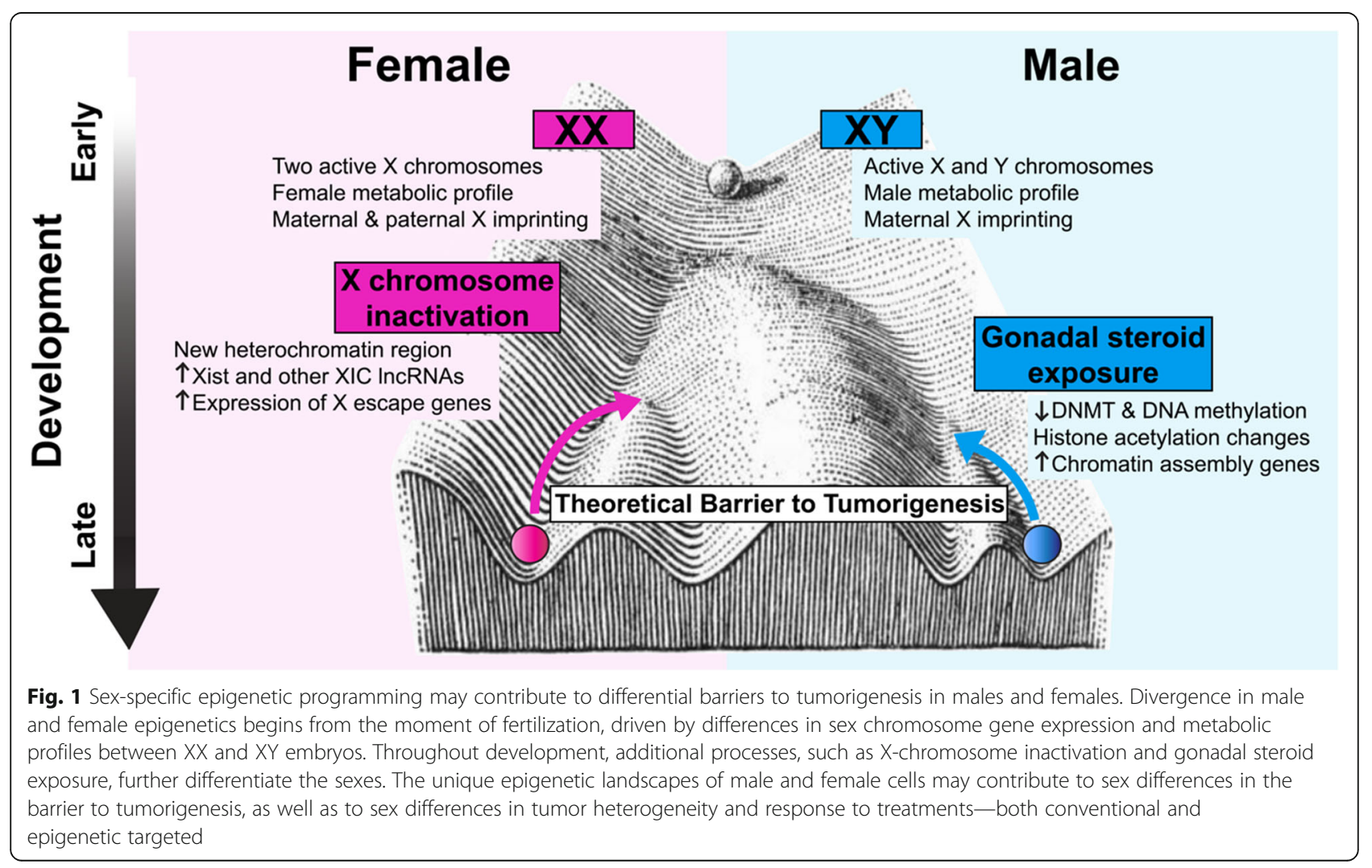


yet been considered. Cancer cells undergo metabolic reprogramming to optimize their biomass and energy production, which allows them to proliferate rapidly. Metabolic reprogramming involves increased uptake of nutrients, increased catabolic metabolism to produce ATP, and increased anabolic metabolism to produce biomass. The latter also requires cancer cells to reprogram mitochondrial metabolism, as many anabolic processes take place in the mitochondria. Furthermore, cancer cells must be able to adapt to the unique metabolic stressors that accompany cancerous growth, including shortage of nutrients, insufficient oxygen supply, and an increase in oxidative stress. Metabolic reprogramming in cancer cells is heavily reviewed elsewhere $[156,157]$. In this section, we will focus on three key components of metabolic reprogramming in cancer: (i) nutrient utilization, (ii) mitochondrial activity, and (iii) reactive oxygen species (ROS) regulation. We will review the literature describing sex differences in these metabolic processes (summarized in Fig. 2) and discuss how these sex differences might contribute to sex disparities in cancer.

\section{Sex differences in metabolism}

Sex differences in metabolism are evident at every stage of life and at the organismal, tissue, and cellular levels. Across multiple species, including mice, bovine, birds, and humans, male embryos grow faster than female embryos and exhibit concordant differences in nutrient utilization and energy consumption [158-163]. In humans, pyruvate and glucose uptake, as well as lactate production, are significantly higher in male embryos [158], and the presence of male fetuses has been associated with elevated maternal fasting plasma glucose $[164,165]$. In cows, a high concentration of glucose selectively blocks development of female embryos during the morula to blastocyst transition [166-168]. Furthermore, glucose metabolism is twice as high in male compared with female bovine embryos [169], and glycolytic genes such as Hexokinase-1, Phosphofructokinase-1, Pyruvate kinase-1/2, GAPDH, and Glucose transporter-1 are all more highly expressed in male bovine embryos [170]. In contrast, female bovine embryos exhibit higher pentose phosphate pathway activity [169]. This sex bias is at least partially due to sex chromosome complement. The pentose phosphate pathway genes glucose-6-phosphate dehydrogenase (G6PD) and O-

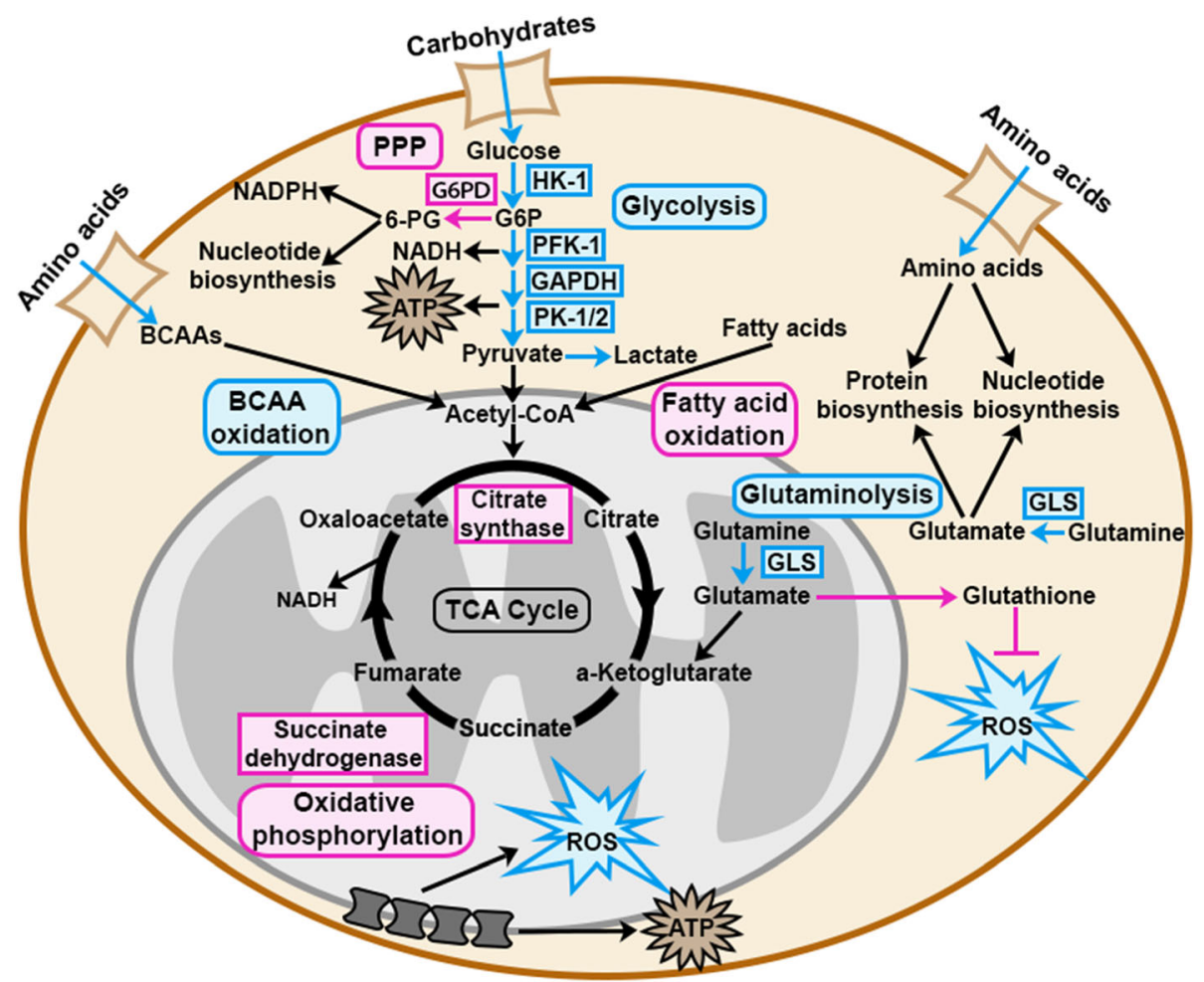

Fig. 2 Sex differences in metabolic pathways may contribute to sex differences in cancer development, progression, and treatment response. During development and throughout adulthood, males and females utilize nutrients differently. Males favor carbohydrate and amino acid metabolism, while females favor fatty acid metabolism. Furthermore, female mitochondria produce less ROS despite their higher mitochondrial activity. These fundamental sex differences in nutrient utilization and mitochondrial activity may contribute to sex differences in metabolic reprogramming in cancer cells, which is important during cancer development, cancer progression, and response to anti-cancer treatment. This schematic focuses on metabolic pathways that are known to be sexually dimorphic and important in cancer. Metabolic pathways, metabolites, and metabolic enzymes shown in blue or pink are known to be higher in males or females respectively 
linked $\mathrm{N}$-acetylglucosamine (GlcNac) transferase (OGT) are located on the X-chromosome and were found to be more highly expressed in female mouse and bovine embryos respectively [171, 172]. In human adults, metabolites of carbohydrate pathways such as glycolysis, gluconeogenesis, and pyruvate, and fructose, mannose, and sucrose metabolism are enriched in male serum compared to female serum [173]. In summary, male embryos exhibit higher glucose uptake and glycolytic activity than female embryos, while female embryos favor the pentose phosphate pathway. In adults, carbohydrate metabolites are enriched in serum of males as compared to females.

Sex differences in amino acid utilization have also been reported. Increased amino acid intake during the first week of life was associated with a significant short-term improvement in weight gain in male, but not female, low birth weight infants $[174,175]$. In human adults, male serum is enriched for amino acid metabolites, including branched chain amino acid metabolites, glutamate metabolites, lysine metabolites, phenylalanine and tyrosine metabolites, cysteine and methionine metabolites, and tryptophan metabolites $[173,176]$. Furthermore, exercising adult men oxidize significantly higher levels of the branched-chain amino acid leucine than exercising women [177]. Additionally, the male rat brain contains higher levels of glutamate and a higher ratio of glutaminase/glutamine synthetase, suggesting that brains of male rats utilize more glutamate from glutamine [178]. Even in moths, adult males oxidize certain amino acids (leucine, phenylalanine, and glycine) at a higher rate than females [179]. Together, these data show that men exhibit higher levels of most amino acid metabolites in their serum, and for those amino acids tested, males exhibit higher rates of metabolism than females, across different ages and species. Whether this is true for all amino acids has yet to be determined.

While the above studies indicate that males exhibit higher rates of glucose and amino acid utilization, females appear to favor lipid substrates for energy metabolism. Upon exercise and during fasting, women utilize more fatty acids while men favor carbohydrate utilization [180]. Numerous publications have shown that lipid metabolism is sexually dimorphic in humans and rodents [181]. Briefly, females exhibit higher rates of lipid biosynthesis than males [182], and enhanced fatty acid clearance in muscle tissue compared to males [183, 184], female rat livers incorporate more fatty acids into glycerolipids and fatty acid oxidation products [185], female rodents and humans are more resistant to free fatty acid-induced insulin resistance [183, 186], and sex differences in expression and activity of lipid metabolism enzymes, such as lipoprotein lipase, are well established [187].
As males and females differ in their fundamental nutrient utilization for metabolism, it is likely that mechanisms of metabolic reprogramming in cancer differ between men and women. For example, reprogramming of amino acid and carbohydrate metabolism may be required for transformation of male cells, while reprogramming of fatty acid metabolism may be required for transformation of female cells. Support for important sex differences in cancer metabolism comes from two publications. In the first, glycolytic gene overexpression in low-grade glioma was shown to correlate with decreased survival in men but not women [188]. In the second, high visceral fat quantity correlated with decreased survival in women with renal cell carcinoma but not men [189]. Thus, sex differences in metabolic reprogramming might contribute to different thresholds for cellular transformation, cancer progression, and outcome, and might therefore contribute to the sex disparity in cancer susceptibility and outcome.

For decades, the primary focus in cancer metabolism research has been on increased nutrient uptake and utilization through aerobic glycolysis (Warburg effect). Today, numerous studies have shown that cancer cells also exploit the mitochondrial tricarboxylic acid cycle (TCA cycle) and oxidative phosphorylation [190, 191]. Mitochondria are a primary source of reactive oxygen species (ROS), and ROS production and consumption through mitochondrial antioxidant pathways, such as glutathione oxidation, are required for well-balanced regulation of ROS levels [192]. Mitochondria exhibit a strong sex-specific behavior as they are exclusively maternally inherited. A vast body of literature describes tissue and cell-specific sex differences in mitochondria morphology, function, and oxidative stress regulation [193]. Here, we will focus specifically on sex differences in the brain; however, since sex differences in mitochondria have been reported in tissues throughout the body, including liver, cerebral arteries, white and brown adipose tissue, pancreas, muscle, and heart, our discussion likely applies to multiple cancer types.

In rat brain, females exhibit higher mitochondrial protein content and higher mitochondrial activity (higher electron transport chain enzyme activity and respiration rate) [194]. These sex differences gradually increase during aging [195]. In concordance with these findings, female mice exhibit an enhanced respiration rate in brain tissue compared to age-matched male mice [196, 197]. Additionally, mitochondria isolated from female mouse brains show higher electron transport chain activity and ATP production than male mitochondria [198]. In contrast, isolated male mitochondria exhibit a higher calcium retention capacity, which can augment ATP production by altering the activity of calcium-sensitive mitochondrial matrix enzymes [199]. Furthermore, 
in vitro cultures of rat cortical astrocytes under low oxygen conditions showed greater respiratory capacity in male, compared to female astrocytes [200]. In human brains, activity of the mitochondrial enzymes citrate synthase, succinate dehydrogenase, and mitochondrial reductase were significantly higher in females, suggesting a higher mitochondrial activity in women compared to men [201]. Sex differences in mitochondrial biogenesis have also been reported but are inconsistent. In the mouse brain, mitochondrial biogenesis is greater in females [197], despite evidence for increased expression of key regulators of mitochondrial biogenesis in males [202]. In contrast, female rat brains have lower mitochondria content than male brains [194], and this sex difference increases with age [195].

Sex differences in mitochondrial activity suggest that ROS accumulation, ROS regulation, and sensitivity to ROS are also sexually dimorphic, as ROS is generated in the mitochondria during oxidative phosphorylation. Indeed, despite their higher respiratory activity, female mouse brains accumulate significantly lower levels of ROS compared to their age-matched male counterparts $[196,197]$. This is also true in rats. A study by Borras et al. showed that female rats exhibit significantly higher expression of antioxidant enzymes, such as glutathione peroxidase and superoxide dismutase. Consequently, female rats exhibit lower levels of ROS, despite their increased respiratory activity, resulting in a better oxidative balance [203]. These findings were complemented by a study from Guevara et al. who showed that antioxidant enzyme levels were higher in female mitochondria [194]. Oxidative damage accumulates in the brain throughout aging. However, in rat brains, the aging effect was less marked in females, which accumulated less oxidative damage as they aged [195]. In humans, biomarkers of oxidative stress are lower in healthy young women than in age-matched men [204]. Together, this data suggests that female mitochondria exhibit a better oxidative balance, accumulating less ROS despite their higher respiratory rate. Thus, female mitochondria appear to be better optimized than male mitochondria.

ROS can be both pro-tumorigenic and antitumorigenic. Certain oncogenic mutations, such as mutations in the Ras pathway, lead to increased ROS levels. In turn, ROS levels can stimulate growth factor signaling pathways, driving tumor development through promotion of proliferation, angiogenesis, invasion, and metastasis [205]. Excessive ROS levels, however, can be cytotoxic, as they can induce apoptosis, autophagy, and necroptosis [206]. Since male mitochondria accumulate more ROS than female mitochondria, male cells may have a higher risk of carcinogenesis than female cells. Furthermore, it has been shown that, with age, ROS levels accumulate more in males than in females [195,
204]. A similar correlation can be found with cancer incidence. With age, cancer incidence rate increases with a steeper slope in men than in women (see "Senescence" section). Therefore, sex differences in mitochondrial activity and ROS regulation may underlie different thresholds for malignant transformation in men and women and might therefore contribute to sex differences in cancer susceptibility.

\section{Implications for targeting metabolism}

In the last decade, metabolic targeting in cancer has made many advances. However, sex has not been adequately considered as a biological variable in cancer metabolism. Here, we will discuss metabolic treatment approaches that are currently in clinical trials for cancer and why they might have sex-specific effects.

Inhibiting the PI3K/mTOR pathway has been shown to be effective in many cancers, and multiple PI3K/ mTOR inhibitors are currently in clinical trials [207, 208]. The PI3K/mTOR pathway is a major regulator of metabolism [209]. Sex differences in metabolic pathways such as glycolysis raise the question of whether the $\mathrm{PI} 3 \mathrm{~K} / \mathrm{mTOR}$ pathway might be sexually dimorphic, and therefore, underlie sex differences in metabolic pathways. In fact, research done in drosophila and murine heart tissue showed that the PI3K/mTOR pathway activity is different in males and females [210, 211], which suggests that targeting this pathway might result in sexspecific responses.

Amino acid metabolism and carbohydrate metabolism have also been targeted in cancer. The effect of the glutaminase inhibitor CB-839 and the effect of a ketogenic diet (low-carbohydrate diet) are both currently being evaluated in clinical trials [212, 213]. Most published data indicate that males utilize more carbohydrate and amino acid substrates for metabolism, while females utilize more fatty acids. Therefore, targeting amino acid and carbohydrate metabolism might have sex-specific effects. Targeting mitochondria to induce apoptosis through increased ROS levels has also been shown to be effective in treating brain cancer in mice, and the mitochondrial-targeting drug dichloroacetate (DCA) has been tested in patients with glioblastoma [214, 215]. Given the large body of literature demonstrating sex differences in mitochondrial activity and ROS accumulation, it is likely that targeting ROS might have different effects in men and women with cancer. Since male mitochondria accumulate more ROS than female mitochondria, male cancers may more readily exhaust their capacity to regulate ROS, and consequently, may respond to ROS elevating treatments more robustly than female cancers. 
Among the notable recent discoveries in cancer genome-wide sequencing was the discovery of the isocitrate dehydrogenase 1 and 2 (IDH1/2) R132H mutation. IDH $1 / 2$ is an enzyme in the TCA cycle that catalyzes the conversion of isocitrate to citrate, and its reverse reaction. Mutant IDH1/2 exhibits loss of normal function and gain of aberrant function, in which isocitrate is converted into D-2-hydroxyglutarate (2-HG), an oncometabolite that has far-reaching pro-tumorigenic effects on epigenetic regulation, DNA repair, and redox state $[216,217]$. Due to its importance for mitochondrial biomass production, oxidative phosphorylation, and fatty acid synthesis, disruption of the TCA cycle through mutant IDH1/2 will most likely result in sexspecific effects during tumor development, progression, and treatment response. In concordance, mutant IDH $1 / 2$ inhibitors, which are currently in clinical trials for multiple cancers [218] might exhibit sexspecific effects. In glioblastoma, a sex-specific effect of IDH mutations on overall survival has been evaluated in multiple publications [56, 59, 219]; however, the findings are inconsistent and further study will be required to define how interaction between IDH1 mutation and patient sex impacts on survival.

\section{p53}

\section{p53 in cancer}

The tumor suppressor TP53 (p53) is the most frequently mutated gene in cancer, with mutations occurring across almost all cancer types and in approximately half of all tumors [220, 221]. p53 is best known as a transcription factor that regulates target genes in response to DNA damage or oncogenic stress to induce cell cycle arrest or apoptosis. In this simplified model, p53 inhibits tumorigenesis by arresting or eliminating preneoplastic cells [222]. Loss of p53 function through mutation or alterations in upstream regulators eliminates this barrier, leading to increased proliferation, genomic instability, and the accumulation of new mutations that drive tumorigenesis. However, p53 actually functions at the center of a complex network of pathways, and can produce many phenotypic outcomes depending on the specific stimulus, tissue or cell type, age, and as described below, sex. In addition to proliferation and DNA damage response, p53 plays important roles in metabolism, pluripotency, epigenetics, ROS regulation, chromatin stability, epithelial to mesenchymal transition (EMT) and invasion, inflammation, and the tumor microenvironment [223]. Currently, tumors are most typically bifurcated into p53-WT and p53-mutant groups, but this is an oversimplification. Mutations in p53 can drive many distinct phenotypes depending on the type of mutation (e.g., missense, truncating, frameshift), co-mutations in other genes, and tissue type [223]. Notably, the most common mutations are missense mutations in the DNA binding domain, many of which have been ascribed with distinct gainof-function abilities that are more oncogenic than complete p53 deletion [221, 224]. Together, this supports that p53 function is context dependent and must be evaluated within each distinct setting to understand its role in cancer. Here, we will review current evidence on sex differences in p53 function and discuss how these sex differences might contribute to the sex disparity in cancer.

\section{Sex differences in $\mathrm{p} 53$}

While p53 is best known for its role as a tumor suppressor, it exhibits sex differences in function across many tissues, throughout normal development and aging. During meiosis, p53 monitors germ cells for DNA damage in males and induces necrosis to eliminate mutant spermatocytes. In female germ cells however, this role is carried out by the p53 family members p63 and p73 [225, 226]. p53 also has differential effects on in utero development. p53 null mice appear developmentally normal but exhibit a sex bias in the ratio of male to female progeny. In the absence of p53, female mice develop neural tube defects that are embryonic lethal. This was recently shown to be caused by incomplete $\mathrm{X}$-inactivation and disruptions in $\mathrm{X}$-gene dosage [227]. p53 directly regulates the long non-coding RNA X-inactivation specific transcript (Xist), which is a primary effector of Xinactivation, and the loss of p53 decreases Xist expression [228].

Sex differences in birth defects in p53 mutant mice may also be related to a sexually dimorphic role for p53 in epigenetic imprinting. Methylation sequencing revealed that female p53 null offspring with birth defects displayed a hypermethylation phenotype for insulin-like growth-factor 2, compared to mice born without birth defects [229], suggesting a female biased role for p53 in monitoring epigenetic marks during development. Work in drosophila also suggests that p53 may be sexually dimorphic in aging. Overexpression of wild type p53 in flies increased the lifespan of males, while decreasing the lifespan of females [230].

An essential function of $\mathrm{p} 53$ is the monitoring of DNA damage and the clearance of pre-neoplastic cells by senescence or apoptosis. A growing body of evidence suggests that the cells-of-origin for GBM are oligodendrocyte precursor cells (OPC) that arise in the subventricular zone (SVZ) before migrating to the cortices [231, 232]. Kim and Casaccia-Bonnefil found that as mice mature, the number of neural progenitor cells in the SVZ decreases faster in males than in females; deletion of p53 eliminated this sex difference. Co-treatment of SVZ cells in vitro with 
radiation and sex hormones revealed that estrogen, but not testosterone, reduced p53 expression and apoptosis in response to DNA damage [233]. This suggests that p53 function in the SVZ is sexually dimorphic during normal development and in response to exogenously induced DNA damage and may contribute to the sex differences in incidence and survival observed in GBM.

Sex differences in p53 function are readily observed in patients with Li-Fraumeni syndrome (LFS). LFS is a familial cancer predisposition syndrome associated with germline mutations in p53 [234, 235]. LFS patients have a $50 \%$ risk of cancer before the age of 30 , and an over $90 \%$ lifetime risk [236, 237]. The most frequent cancer types include breast cancer, soft tissue sarcoma, brain/ CNS tumors, bone sarcoma, and adrenocortical carcinoma. Even when controlling for the high rate of female breast cancer, multiple LFS family cohort studies have concluded that female mutant p53 carriers have an increased risk of developing cancer compared to male carriers [236-239]. Importantly, the numbers of mutant p53 carriers were equivalent between males and females, suggesting that males and females have differential responses to the same mutations in p53, leading to greater risk of cancer development in females. However, Oliver et al. contradict these findings [240]. They observed that mutant p53 carriers exhibited a male bias in cancer incidence that matched the male bias in incidence observed in individuals with sporadic p53 mutations. All five studies, however, reported a female bias in adrenocortical carcinoma (ACC) incidence, which is corroborated by data reported by the International Pediatric Adrenocortical Tumor Registry [241]. Pediatric ACC is a rare cancer $(0.72 /$ million/year in the USA) and is strongly associated with mutations in p53 [242]. Because many of these patients are prepubescent, these data provide further support that males and females respond differently to p53 mutations in a tissue-specific manner, and that these differential responses cannot be explained by the effects of circulating sex hormones.

The p53 pathway, encompassing p53 and its upstream regulators, is mutated in approximately $84 \%$ of primary GBM tumors [243]. In primary astrocytes lacking the tumor suppressor neurofibromin (NF1), p53 loss is sufficient to induce sex differences in transformation, leading to greater proliferation and clonogenic frequency in male cells compared to female cells. Furthermore, this p53 loss contributed to sex differences in in vivo tumorigenesis. When otherwise isogenic male and female astrocytes lacking functional NF1 and p53 were injected into the brains of both male and female mice, the mice injected with male cells were more likely to form tumors, regardless of the sex of the host mouse [35]. This finding was replicated in a second model of GBM, in which NF1 and p53 were knocked-out in utero by injecting clustered regularly interspaced short palindromic repeats (CRISPR)/CRISPR-associated protein 9 (Cas9) constructs into the lateral ventricles of E14 mouse embryos, and electroporating to target progenitor cells in the SVZ. While all mice developed GBM, males developed tumors and succumbed to their disease faster than females [21]. Depletion of the tumor suppressors $R B 1, C D K N 2 A$ (p16), or CDKN1A (p21) in females eliminated this difference, suggesting female astrocytes possess at least partial compensatory mechanisms for cell cycle regulation in the absence of p53 [21,35], which contribute to the greater barrier to tumorigenesis in these cells.

In addition to the direct effects of p53, some p53 regulators may also contribute to sex differences in cancer. The E3 ubiquitin-protein mouse double minute 2 homo$\log (\mathrm{Mdm} 2)$ is a direct regulator of p53 protein stability [244]. Under normal conditions, Mdm2 binds and ubiquitinates p53 leading to proteasomal degradation [245]. In response to cell stress, p53 is phosphorylated, preventing $\mathrm{Mdm} 2$ interaction and subsequent degradation [246]. In many tumors with WTp53, the p53 pathway is suppressed through amplification and overexpression of Mdm2 [247]. MDM2 SNP 309 is a T/G single nucleotide polymorphism in the promoter of $M D M 2$ that increases affinity for the transcription factor Sp1, driving increased expression of Mdm2 mRNA and protein [248]. The T/G allele drives an estrogen-dependent increase in cancer risk in females [249]. A recent study by Haupt et al. identified a network of X-linked genes associated with p53 function [250]. They found that mutations in p53 regulatory genes on the X-chromosome were expressed at the mRNA level less frequently in females than in males with the same mutation. This increased rate of non-expressed mutations occurred more frequently in p53 pathway linked-genes than unaffiliated genes, suggesting that females may be able to protect the p53 pathway through selective inactivation of mutant genes on the $\mathrm{X}$-chromosome.

\section{Implications for targeting p53}

p53 has garnered considerable support over the last two decades as a candidate target for cancer treatment. Primarily, attempts at targeting p53 have relied on one of three methods: (1) introduction of exogenous WTp53, (2) inhibition of negative regulators of p53 such as Mdm2, or (3) small molecules that can force mutant p53 into a wild type conformation with normalized function [251, 252]. Each of these methods is based on the observation that WTp53 is induced in response to oncogenic stress, so that reactivation of the p53 pathway may slow or eliminate cancer. Given the growing body of evidence for sex differences in p53 function, p53 regulators, and tumor initiation and progression, preclinical and clinical 
studies focused on targeting p53 should be powered to identify sex differences in treatment response.

\section{Cellular senescence}

Senescence and cancer

Cellular senescence is the process of permanent cell cycle arrest that occurs in response to cellular aging or DNA instability. Senescence primarily acts as a tumor suppressor mechanism, by preventing continued proliferation of damaged, potentially tumorigenic cells [253, 254]. Despite cell cycle exit, senescent cells remain metabolically active and release factors known as the senescence-associated secretory phenotype (SASP) [253255]. SASP can have both pro- and anti-tumorigenic effects on the tissue landscape [254, 256-260]. Antitumorigenic SASP factors can induce senescence in neighboring cells to safeguard against tumor formation, or recruit immune cells for clearance of tumor cells and senescent cells $[254,256,257,260,261]$. Protumorigenic SASP factors can facilitate malignant transformation, promote proliferation, and disrupt tissue structure, tissue function, and/or immune activity to create a tumor promoting environment [255, 259]. Adding to this complexity, senescent cells express distinct SASP profiles that depend on multiple variables, including cell-of-origin, tissue-of-origin, and cause of senescence [253, 255]. For example, Ras-induced senescent human fibroblasts secrete greater levels of factors that promote transformation, compared to senescent fibroblasts induced by replicative exhaustion or irradiation [262]. In mice, Ras-induced senescent hepatic cells produce SASP that suppresses hepatocellular tumorigenesis, by increasing cell clearance [263]. In contrast, Pten-loss-induced senescent prostate cells release cytokines that generate a pro-tumorigenic environment, characterized by increased immunosuppressive myeloid-derived suppressor cells (MDSC) and decreased lymphocyte activity [264]. In these ways, senescent cells and SASP play a dynamic and complex role in cancer development, progression, and response to treatment. Here, we will review the current evidence on sex differences in senescence, and discuss how these differences might contribute to sex disparities in cancer.

\section{Sex differences in senescence}

Worldwide, women live longer than men [265, 266], and numerous age-associated diseases-including cardiovascular diseases, neurodegenerative disorders, and cancer-exhibit sex differences in presentation, response to treatment, and mortality [267]. Senescent cells and SASP are important mediators of normal and pathological aging phenotypes. Baker et al. presented that the elimination of senescent cells in mouse models attenuates ageassociated changes in multiple tissues. Briefly, senescent cell clearance was associated with greater muscle fiber diameter, preserved muscle function, greater fat deposits, and delayed onset of lordokyphosis and cataracts [268]. In a subsequent study, the group further showed that the clearance of senescent cells led to improved structure and function of the kidney and heart, as well as an increased general healthspan, increased lifespan, and increased tumor latency [269]. Recently, Ruhland et al. showed that senescent cells increase local inflammation in both mouse models and human skin, and that SASPderived cytokines can promote MDSC infiltration to generate a tumor-permissive environment [259]. These studies support that the accumulation of senescent cells and the release of SASP can have significant impacts on the tissue landscape and can result in tissue dysfunction, inflammation, and tumor formation. Accordingly, numerous studies have demonstrated that senescent cells and SASP are major contributors to multiple ageassociated pathologies, such as neurofibrillary tangles, atherosclerosis, osteoarthritis, and cancer [254-257, 259-261, 268-274], which also exhibit significant sex differences in incidence and severity. Given the substantial sex differences in aging and age-associated pathologies, and the evidence that senescence-associated changes in tissue homeostasis mediate many of these pathologies, it seems likely that sex differences in senescence could be a contributing factor. However, this has yet to be investigated directly.

Cancer incidence and prevalence rates rise more steeply in males than females with increasing age (Fig. 3) [275]. Whether this is a consequence of sex differences in cellular senescence is unknown. Cells activate senescence as a protective response to DNA-damaging stressors, including telomere attrition, oncogene activation, oxidative stress, and drug/toxin exposure [276279]. The induction of senescence depends on: (1) the magnitude of genotoxic stress and (2) cellular thresholds for senescence activation; sex may affect both factors. On average, males have shorter telomere lengths than age-matched females, and male cells exhibit faster rates of telomere attrition than female cells [280]. Consequently, male cells may encounter telomere dysfunction sooner than female cells. Furthermore, male cells are more prone to oxidative damage (see "Metabolism" section) and accumulate more somatic mutations than female cells [280]. Together, these studies suggest that males may have a greater risk of exposure to DNAdestabilizing events than females. Finally, there may be sexual dimorphism in toxin metabolism, which can result in sex differences in vulnerability to drug-induced damage. Males and females express distinct activity levels of cytochrome-P450 (CYP450) and UDPglucuronosyltransferase (UGT) isoforms-two essential enzymatic families involved in drug metabolism [281, 


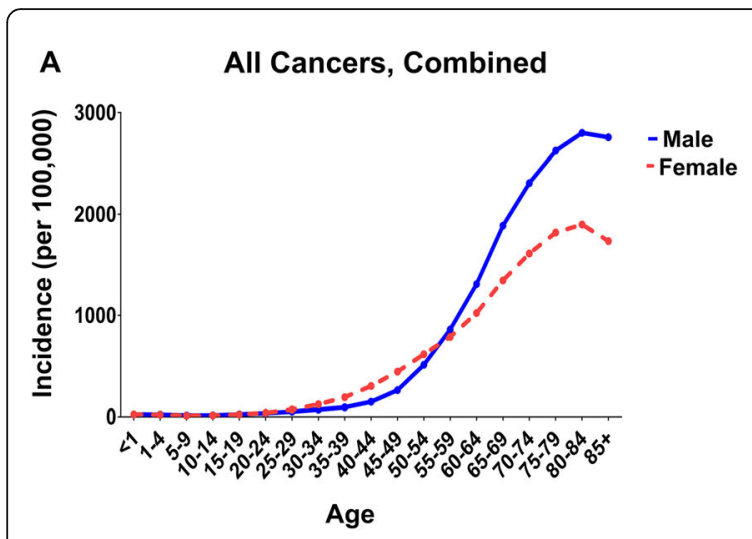

B

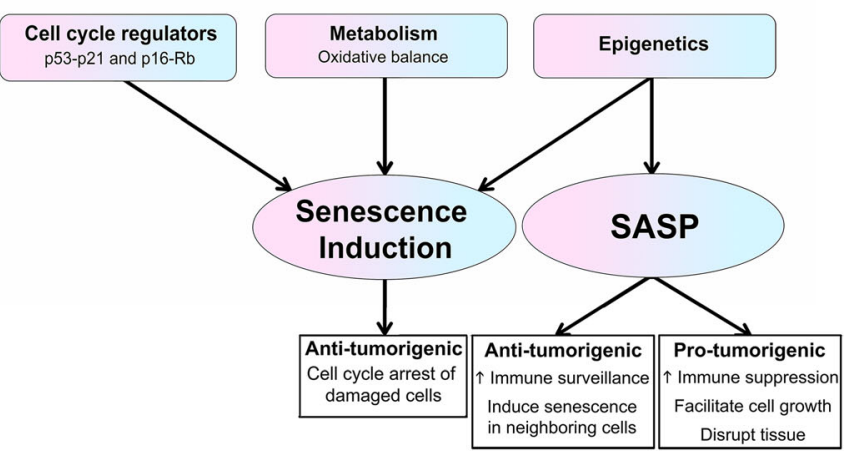

Fig. 3 Sex differences in senescence and SASP may contribute to the increasing sex disparity in cancer incidence with age. a Cancer incidence increases more steeply in males than in females with age, according to SEER explorer data from 2012-2016 ${ }^{266}$. b Sex differences in cell cycle regulators, metabolism, and epigenetics can all result in sex differences in senescence activation and SASP. Senescence induction can decrease the risk of transformation in damaged or aged cells, whereas SASP can have both anti-tumorigenic and pro-tumorigenic consequences on the aging tissue. In this way, sex differences in senescence and SASP may contribute to the observed age and sex effects on cancer

282]. However, the significance of these results to understanding sex differences in drug metabolism and druginduced cellular damage remains to be elucidated.

While males may exhibit greater DNA damage than females, they may not necessarily activate senescence more frequently. DNA damage activates DNA-damage response (DDR) kinases, such as ATM or ATR [253, 283]. When the damage is determined as irreparable, DDR kinases upregulate the $\mathrm{p} 53-\mathrm{p} 21$ and $\mathrm{p} 16^{\mathrm{INK} 4 \mathrm{a}}-\mathrm{Rb}$ pathways, resulting in either senescence or apoptosis [253, 283]. Interestingly, under some circumstances, damaged cells remain proliferative despite these protective mechanisms. There may be sex differences in the degree of activation and consequences of these pathways. Malorni et al. found that male and female vascular smooth muscle cells (VSMC) exhibit distinct responses to DNA-damaging stress. After irradiation, male VSMCs more readily underwent apoptosis, whereas female VSMCs expressed senescence characteristics [284]. While sex hormones partially contribute to this sex difference in cell fate [285], cell-intrinsic sex differences are likely involved as well. As described above, there is evidence for sexual dimorphism in cell cycle regulatory pathways (see "p53" section). Notably, after loss of NF1 and p53 function, female astrocytes were more likely to upregulate $\mathrm{Rb}, \mathrm{p} 16$, and $\mathrm{p} 21$-cell cycle regulators involved in senescence-and were less likely to undergo malignant transformation compared to male astrocytes [21, 35]. DNA damage repair, apoptosis, and senescence, each serve as barriers to transformation. However, these pathways are interconnected, and dysfunction in key regulators can affect more than one safeguard. For example, loss of p53 function can compromise both DNA damage repair and pro-apoptotic pathways [286], and activation of compensatory mechanisms such as senescence becomes necessary to avoid transformation. Thus, a male resistance to activating regulators of senescence likely increases their risk for transformation and may contribute to the observed male risk for cancer (Fig. 3).

After senescence induction, the subsequent clearance of senescent cells is important to minimize the accumulation of senescent cells in tissue. As detailed above, the accumulation of senescent cells is associated with multiple age-related diseases, and the elimination of senescent cells leads to increased healthspan, increased lifespan, and the mitigation of age-associated phenotypes and pathologies [254-257, 259-261, 268-274]. A recent study revealed that in both aged wild type mice (30 months) and progeroid mice, males express significantly greater levels of $p 16$ and $p 21$ mRNA in the liver, kidney, and spleen than age-matched females. This sex disparity was decreased in wild-type mice at the extremes of old age (35 months): p16 mRNA levels remained significantly lower in the liver and spleen of females compared to males, while $p 21 \mathrm{mRNA}$ levels in the spleen were significantly greater in females than males [287]. These results suggest that males bear a larger load of senescent cells than females throughout aging, which may be influencing the increased male risk for various age-related pathologies, including cancer.

Finally, as mentioned above, senescent cells can also contribute to tumorigenesis through the release of SASP. Given the heterogeneous nature of SASP, sex also may influence the magnitude and/or types of factors released. Yet no studies have investigated sex effects on SASP or how sex differences in SASP affect tumor development or growth.

\section{Implications for targeting senescence}

With increasing age, tissue structure and function are increasingly influenced by the accumulation of senescent 
cells and the effects of their SASP. This has a significant effect on disease, including cancer. Furthermore, irradiation and chemotherapy, which are mainstays of anticancer therapy, can activate therapy-induced senescence (TIS) in cancer cells and neighboring cells. This has been associated with increased therapy-associated toxicity and increased risk for cancer recurrence [288]. For these reasons, there has been growing interest in adjuvant therapies that target senescence to improve treatment response and reduce risk of relapse. These include senescence-inducing drugs, SASP-inhibiting agents, senolytics, senostatics, and synergistic therapies [289, 290]. The development of senescence-targeting drugs is still relatively young, and most agents are undergoing preclinical testing on animal and xenograft models with mixed results. However, there have been recent advances in the field. Particularly, the FDA recently approved palbociclib, a CDK4/6 inhibitor and senescence-inducing agent, for use in ER+/HER2-advanced breast cancer patients [291]. There are also multiple clinical trials studying the efficacy of the combination therapy of navitoclax, a senolytic agent, and chemotherapy against various cancer types. Unfortunately, completed studies show no change in the objective response rate [292]. A common obstacle in the development of senescence-targeted treatments is the lack of a clear understanding of the senescence response and SASP. Further investigation into the mechanisms involved will be integral to formulating more effective treatment strategies, and it is likely that sex-adapted approaches to targeting senescence will be required for the greatest success.

\section{Immunity}

\section{Immune system in cancer}

The immune system plays a significant role in cancer development and progression [293]. This has led to the inclusion of "evading immune destruction" as a hallmark of cancer [294]. There are numerous mechanisms by which tumors avoid immune responses, such as suppression of regulatory $T$ cells [295], down-modulation of antigen processing [296], induction of immune suppressive mediators [297], and promotion of tolerance and immune deviation [298, 299]. As adult females generally mount stronger innate and adaptive immune responses than males [47, 300], sex differences in the immune system likely contribute to the sexual disparity in incidence and mortality associated with certain cancers. Here, we will discuss sex differences in the immune system, and how these differences can lead to sex differences in cancer incidence, mortality, and treatment efficacy.

\section{Sex differences in the immune system}

In the innate immune system, females have antigenpresenting cells (APCs) that are more efficient at presenting peptides than males [301]. As cancer cells modulate antigen-presentation to evade immune destruction, sex differences in APCs and their downstream effector cells can have significant impact on anti-tumor immunity and immunotherapy responses. For example, B7-homolog 1 (B7-H1), a co-signaling molecule expressed abundantly on APCs, which contributes to tumor immune evasion and induces $\mathrm{T}$ regulatory cell (Treg) function [302], has been found to be modulated in an estrogen-dependent manner. As a result of reduced Treg function allowing for antitumor immunity, female B7-H1 knock-out mice are more resistant to syngeneic B16 melanoma tumor formation than males [303]. Females also have been shown to have higher numbers and greater phagocytic activity of macrophages and neutrophils than males [304, 305]. Hepatocellular carcinoma (HCC), the most common liver cancer, is 3 to 5 times more likely to develop in males than females [306]. In a mouse model of HCC using a chemical carcinogen, diethylnitrosamine (DEN), it was found that IL6 production by Kupffer cells $(\mathrm{KC})$, resident liver macrophages, was higher in males than females. IL- 6 has been found to be in large concentrations in the tumor microenvironment and is deregulated in cancers [307]. Estrogen reduced circulating IL-6 levels in DEN-treated mice, providing a potential explanation for the reduced liver cancer risk in females [27]. Additionally, there exists a large sex disparity in lung cancer oncogenesis following epithelial Stat3 deletion in mice with induced mutant $K$ ras. In males, the absence of epithelial STAT3 promotes lung tumorigenesis via enhanced IL-6 [308] signaling and neutrophilic inflammation, which is inhibited in females by estrogen signaling. These studies suggest that estrogen may inhibit inflammatory cytokine secretion by macrophages and neutrophils, reducing cancer risk in females. Conversely, women have a higher incidence of non-small cell lung cancer (NSCLC) [309], but have been shown to have better prognoses than males [29]. It has been suggested that sex differences in NSCLC are due to immune differences, as female NSCLC patients exhibit significantly different immune gene set enrichment compared to males [310].

Within the adaptive immune system several key immune-related genes, such as FOXP3 and CD40L, are located on the X-chromosome. Also, numerous genes expressed in $\mathrm{T}$ cells carry the estrogen response element in their promoters, leading to stronger inflammatory and cytotoxic $\mathrm{T}$ cell responses in females. These include IFN- $\gamma$, IFI6, CX3CL1, CX3CL2, IL-1, IL-5, and IL-16 [311]. The two estrogen receptor subtypes (ER $\alpha$ and ER $\beta$ ) are expressed on $T$ cells and $B$ cells, suggesting a direct regulatory role of estrogens on these cell types [312]. In humans, CD4+ T cells from females produce higher levels of IFN- $\gamma$ and proliferate more than male 
CD4+ $\mathrm{T}$ cells. However, male CD4+ $\mathrm{T}$ cells have increased IL-17A production compared to females [313]. IL-17A has been shown to have the ability to both increase tumor progression by activating angiogenesis and immunosuppressive activities, and inhibit tumor progression, through recruitment of immune cells into tumors and stimulation of effector CD8+ T cells [314]. Sex differences in $\mathrm{T}$ cells of animal models are more pronounced, with CD4+ T cells from females being associated with increased production of IFN- $\gamma$ and increased responsiveness to IL-12 through STAT-4 activation $[312,313]$. These data suggest that the more robust $\mathrm{T}$ cell response in females may be beneficial for antitumor immunity. Thus, immunological sex differences in the innate and adaptive immune system, due to both sex hormones and X-linked genes, could contribute to the etiology of sex-related cancer disparities.

\section{Implications for immunotherapy}

Despite known sex differences in immune responses and functions (Fig. 4), the effect of sex on cancer immunotherapy was not investigated until recently. Successful immunotherapy could enhance the ability of the immune system to mount an effective neo-antigenspecific antitumor response, or stimulate the immune system more generally to mount a vigorous immune response [315]. At least three sites of immune action can be targeted for therapeutic intervention: promoting antigen presentation by dendritic cells (DCs), promoting the production of protective $\mathrm{T}$ cell responses, and overcoming immunosuppression in the tumor microenvironment. Estrogens are important regulators of the development and function of DC precursors and DC cell subsets, including plasmacytoid DCs (PDCs), which are a high priority immunotherapy target [316, 317]. Furthermore, females exhibit higher CD4+ $\mathrm{T}$ cell counts and higher CD4/CD8 ratios, whereas males have higher numbers of CD8+ and Tregs [47, 318]. Immunotherapies rely on effective antitumor immunity in the tumor microenvironment, which can be achieved by recruiting tumor-infiltrating leukocytes to the site [315]. As leukocyte populations are dramatically affected by sex, antitumor immune responses may display sexual dimorphisms that impact on the efficacy of cancer immunotherapies [319].

Anti-tumor immunotherapy treatments can be antigen-specific, as in monoclonal antibodies, vaccines, and CAR-T cells. There are also antigen-agnostic therapies, such as oncolytic virus therapy and immune checkpoint inhibitors (ICIs), which act as inhibitors of programmed cell death receptor 1 (PD-1) and cytotoxic T-lymphocyte-associated protein 4 (CTLA-4). ICIs have been shown to significantly prolong the overall survival of patients with advanced tumors, by restoring efficacious antitumor immunity [320]. However, these therapies have disproportionately increased efficacy in male compared to female patients [3, 321]. It has also been shown that tumor mutational burden, rather than PD-L1 expression, has a much better predictive power for female response to ICI compared to male response, in lung cancer patients [322]. Furthermore, women experience more immune-related adverse effects compared with men during treatment with anti-PD-1 drugs [323].

The molecular basis for sex differences in response to ICI treatments remains to be fully explored. To date, preclinical studies have demonstrated that the PD-1 ligand (PD-L1)/PD-1 pathway can be regulated by sex steroids [316, 324]. Furthermore, PD-L1 expression has

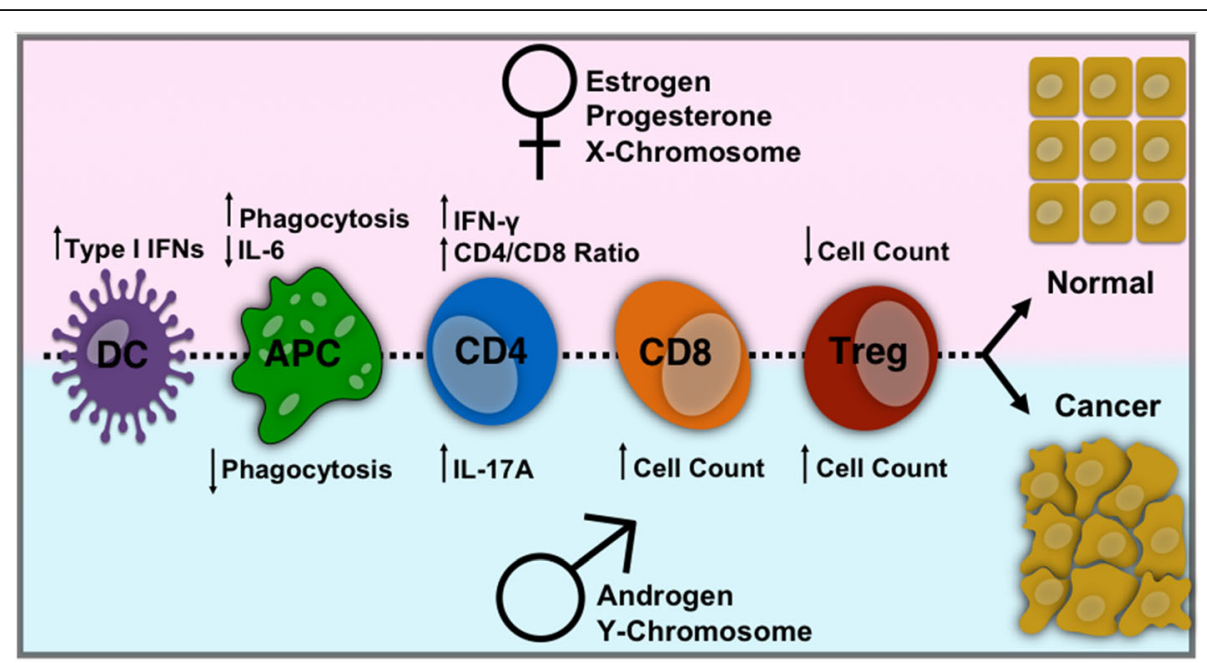

Fig. 4 Sex differences in immune cells affecting cancer development. Effects of gonadal hormones and sex chromosomes on cells of the innate and adaptive immune system affecting cancer development. Pink shaded region refers to female differences, and blue shaded region refers to male differences. See text for details 
been shown to be modulated by several X-linked microRNAs (miRNAs), such as miR-221, miR-222, miR106b, miR-20b, and miR-513 [325]. The X-linked miR424 targets both PD-L1 and CD80, resulting in regulatory control of both the PD-L1/PD-1 and CD80/CTLA-4 pathways [326]. Since mechanisms affecting X-linked genes, such as silencing escape and $\mathrm{X}$-inactivation skewing, could also influence X-linked miRNAs, it is possible that these miRNAs contribute to sex differences in the immune system [327].

As the PD-L1/PD-1 and CD80/CTLA-4 pathways are important targets for ICIs, it is crucial to consider their sexual dimorphism during immunotherapy. For example, as estrogen increases intracellular PD-1 expression [324], female patients may need a higher dose of an ICI to achieve equal immunotherapy efficacy as males. Likewise, as males and females have different numbers and phenotypes of $\mathrm{T}$ cell subsets, it may be beneficial to target a specific cell population in each sex to mount effective antitumor immunity. Accordingly, it is critical to consider sex differences in immune functioning and responses when designing cancer preclinical and clinical studies.

\section{Angiogenesis}

\section{Angiogenesis and cancer}

Angiogenesis, the formation of new blood vessels from pre-existing ones, is a hallmark of cancer [294, 328]. Blood vessels are primarily composed of endothelial cells (ECs), which interconnect through tight junctions to form the endothelial lining. Notably, in healthy adults, the vasculature remains quiescent under normal conditions, except for ECs in the female reproductive tract during menstrual cycles and pregnancy [329]. Within the hypoxic tumor microenvironment, abundant proangiogenic growth factors are released, including vascular endothelial growth factors (VEGFs), fibroblast growth factors (FGFs), and platelet-derived growth factors (PDGFs) [330-332]. These pro-angiogenic factors bind to pro-angiogenic receptors on ECs, such as VEGF receptor-2 (VEGFR2) [333-336] and integrins [337, 338], and activate downstream signaling pathways like PI3K/Akt [339], leading to endothelial nitric oxide synthase (eNOS) activation [340]. Activated ECs secrete proteases such as matrix metalloproteases (MMPs) to dissolve local basement membrane and extracellular matrix (ECM), allowing ECs to migrate towards the angiogenic stimuli [341]. The signaling events further increase EC proliferation, survival, and differentiation, allowing new capillaries to form and elongate [342, 343]. During angiogenesis, bone marrow-derived endothelial progenitor cells (EPCs) are recruited to the endothelial lining of new blood vessels through vasculogenesis [344]. Other key cell types involved in this angiogenic process include macrophages, pericytes, and fibroblasts [345348]. In healthy tissue, the process of angiogenesis is tightly regulated by the balance of pro-angiogenic and anti-angiogenic factors, whereas in cancer, this balance is altered to sustain tumor growth, development, and metastasis [342, 349]. Here, we will review current evidence on sex differences in angiogenesis, and discuss how these differences may contribute to sex differences in cancer.

\section{Sex differences in angiogenesis}

Evidence for sex differences in tumor angiogenesis is limited, with one recent study showing more lymphangiogensis and angiogenesis in lung adenocarcinoma from young female patients than from men [350]. However, several sex differences in EC phenotypes and genotypes, EPC mobilization, circulating angiogenic factors, perivascular tissues, and effects of sex hormones on angiogenesis have been described, thus providing a template for studying sex differences in tumor angiogenesis (Fig. 5).

Female and male ECs present intrinsically different angiogenic phenotypes, and increasing evidence indicates that angiogenesis in males and females may be dependent on different mechanisms. Human umbilical endothelial cells (HUVECs), a macrovascular cell model commonly used for endothelial studies in vitro, when isolated from female newborns, show higher migration ability compared to cells isolated from males [351]. This finding aligns with an ex vivo study that shows faster migration in female macrovascular ECs from rat skeletal muscle compared to male samples [352]. The sexual dimorphism in EC migration ability may be a consequence of female ECs expressing more cell adhesion molecules, including Integrin $\alpha v \beta 3$ [352], which promote EC migration through mediating cell-matrix and cell-cell association [337]. Female ECs express higher eNOS and VEGFR2, which may further modulate EC proliferation and migration [351, 353, 354]. Conversely, HUVECs from male newborns are more autophagic than female cells [351]. As EC autophagy has emerged as a critical mechanism facilitating tumor angiogenesis [355], this sex difference in autophagy may contribute to sex differences in tumor angiogenesis, tumor growth, and response to anticancer therapy. Moreover, one study found that female EC sprouting relies on eNOSmediated migration, while male capillary outgrowth is independent of eNOS but requires cell proliferation [354], suggesting that mechanisms in angiogenesis may be different for male and female ECs. Together, these findings suggest female ECs facilitate angiogenesis mainly through integrin, VEGFR, and eNOS-mediated migration, while male ECs may be less migratory but 


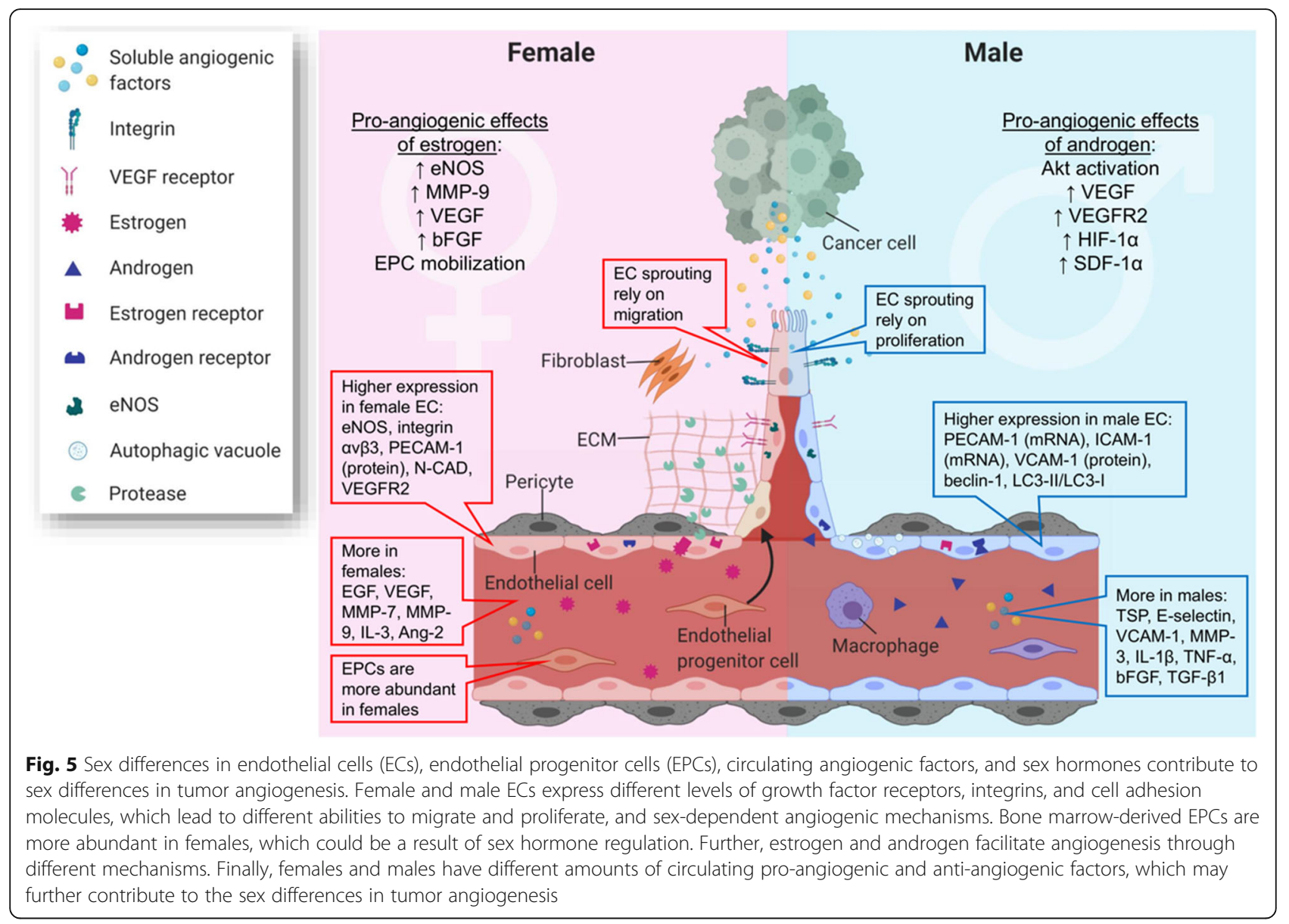

can still promote angiogenesis through proliferation and other underexplored mechanisms such as autophagy.

In addition to the intrinsic sex differences in ECs, effects of sex hormones, especially estrogen, on angiogenesis have been extensively examined [352, 356, 357]. Studies have identified the expression of ER, progesterone receptor (PR), and androgen receptor (AR) on both ECs and EPCs [351, 358-361]. Androgen was reported to promote proliferation, migration, and angiogenesis in male ECs but not female ECs, both in vitro and in vivo, by the regulation of key angiogenesis-related genes, including HIF- $1 \alpha$ and SDF-1 $\alpha$ [362]. Estrogen, specifically estradiol (E2), causes rapid eNOS production and increases EC proliferation and migration via ER $\alpha$ and ER $\beta$; although, multiple studies reported that ER $\alpha$ may play a more significant role $[357,359,361]$. E2 can induce bone marrow-derived EPC mobilization via ER binding, followed by PI3K pathway activation, eNOS induction, and FGF-2 production [357]. This E2-mediated EPC mobilization may explain the higher number of EPC (CD34+ VEGFR2+) observed in pre-menopausal women, whereas no significant difference was found between post-menopausal women and age-matched men [363].
E2 has also been found to modestly correlate with hematopoietic progenitor cell counts in women [364]. Interestingly, similar E2-mediated EPC mobilization was also observed in male mice with hindlimb ischemia [356, 365]; additionally, a higher number of EPCs were observed in men with cardiovascular diseases than agematched women [357], suggesting hormonal regulated angiogenesis may be confounded by cardiovascular diseases. In addition to ECs and EPCs, emerging evidences show that estrogen has an effect on a wide variety of cells in the perivascular environment, including tumor cells, smooth muscle cells, fibroblasts, pericytes, macrophages, and adipose tissue, which can indirectly upregulate angiogenesis by induction of pro-angiogenic factors such as VEGF [366-369]. Together, these estrogenmediated pro-angiogenic effects align with preclinical and clinical evidence, where a positive correlation between ER expression, angiogenic activity, tumor size, and invasiveness was observed for several cancer types, including breast cancer and lung cancer [350, 370-372].

Sex differences are also evident in the abundance of circulating angiogenic factors. One study of platelet-rich plasma found that pro-angiogenic factors, including 
epidermal growth factor (EGF), insulin growth factor-1 (IGF-1), PDGF-BB, and VEGF, were significantly higher in women [373]. Conversely, another study of plateletrich plasma found that PDGF-BB was higher in men and found no sex differences in IGF-1 levels [374]. The same study also found that interleukin-1 beta (IL-1 $\beta$ ) and several angiogenic growth factors, including tumor necrosis factor-alpha (TNF- $\alpha$ ), basic fibroblast growth factor (bFGF), and transforming growth factor-beta 1(TGF- $\beta 1$ ) were higher in males [374]. Further studies do not show a strict pro-angiogenic correlation in females versus males in serum; anti-angiogenic factor angiopoietin-2 and pro-angiogenic factor IL-3 were higher in females, while anti-angiogenic thrombospondin (TSP) and several pro-angiogenic endothelial adhesion molecules (E-selectin, VCAM-1) were higher in males [375]. The same study also showed that MMP-7 and MMP-9 were more abundant in female serum, whereas MMP3 was higher in male serum [375]. These results indicate a need for meta-analysis to determine if correlations exist between pro- vs. anti-angiogenic factors and sex. Further, these findings suggest a need to uncover why certain growth factors, cytokines, and proteases have sexually dimorphic expression, and whether these sexual dimorphisms translate to differential angiogenic signaling and function.

\section{Implications for targeting tumor angiogenesis}

Since 2004, 14 anti-angiogenic drugs have been approved by the Food and Drug Administration [376]. Primary methods for targeting tumor angiogenesis have relied on antibody inhibitors that block angiogenic growth factors such as VEGF, PDGF, and their signaling pathways [377, 378]. There is already evidence showing sex-dependent response to bevacizumab, a monoclonal antibody that blocks VEGF [379381]. As increasing evidence demonstrates sex differences in survival outcomes of cancer and responses to therapies [59, 382], preclinical and clinical studies focused on inhibiting angiogenesis should be powered to identify sex differences in treatment response. Furthermore, systematic analysis is necessary in discovering sex-specific molecular targets for anti-angiogenic therapies.

Systems biology offers a promising approach to discover sex-specific molecular targets, and thereby improve anti-angiogenic therapy. Previously, angiogenic receptors on ECs and other perivascular cells have been extensively characterized [336, 353, 383-386] and computationally modeled [387-390]. Computational models, based on mass-action kinetics of the signaling axis, have characterized VEGF-VEGFR binding in both healthy and diseased tissue [391, 392], VEGF spatial distribution in skeletal muscle [393-395], angiogenic sprouting in skeletal muscle [396, 397], and VEGF gradients in peripheral artery disease (PAD) [398]. A recent computational model, which incorporated ex vivo VEGFR concentrations from breast cancer xenografts, predicted that tumors having "high" concentrations of plasma membrane VEGFR1 could be resistant to anti-VEGF drugs (angiogenesis inhibitors) [384, 399]. This systems biology approach, which combines computational modeling and quantitative profiling of the biological system, can similarly predict how sex differences in angiogenic factors and cell receptors can result in differential antiangiogenic drug response.

\section{Statistical considerations}

In order to optimally detect sex differences in cancer mechanisms like those described above, investigators in the laboratory and the clinic must move beyond simple comparisons of males versus females using $t$ tests to evaluate the significance of their differences. Popular analysis strategies for assessing sex differences in cancer are either incorrect or insufficient. Sex differences cannot be inferred from a two-way ANOVA with sex and treatment only; the analysis must include treatment and sex interaction. It is simple and appealing to conduct simple two sample $t$ tests to compare treatment within each sex, but this practice is inefficient and insufficient, since no formal inference can be made on the sex difference. Even if an interaction term is incorporated into an ANOVA model, how to derive the contrast to appropriately estimate sex differences is not trivial for most researchers. Appropriate study design, statistical modeling, and tests are required for detecting that interaction. Here, we will briefly consider the necessary components to perform rigorous evaluations of sex effects in cancer.

While completely randomized treatment assignments among a cohort of mice of both sexes is a valid approach to study an interaction effect, deviation from balanced treatment assignments to the two sexes will critically reduce the efficiency of detecting interactions. More effective detection of interactions between treatment and sex, as well as their main effects, can be achieved with a balanced two by two $(2 \times 2)$ factorial design. Proper implementation of the factorial design requires randomization and blinding, fundamentals of clinical trial design that are often missing in animal experiments.

To illustrate the essential statistical aspects, we evaluate a treatment efficacy outcome, which can be quantitative, binary, or time to event, of two treatments (vehicle vs. treatment) that may differ by sex (female vs. male). Statistical interaction can be visualized by line plots as shown in Fig. 6. Clinical efficacy 


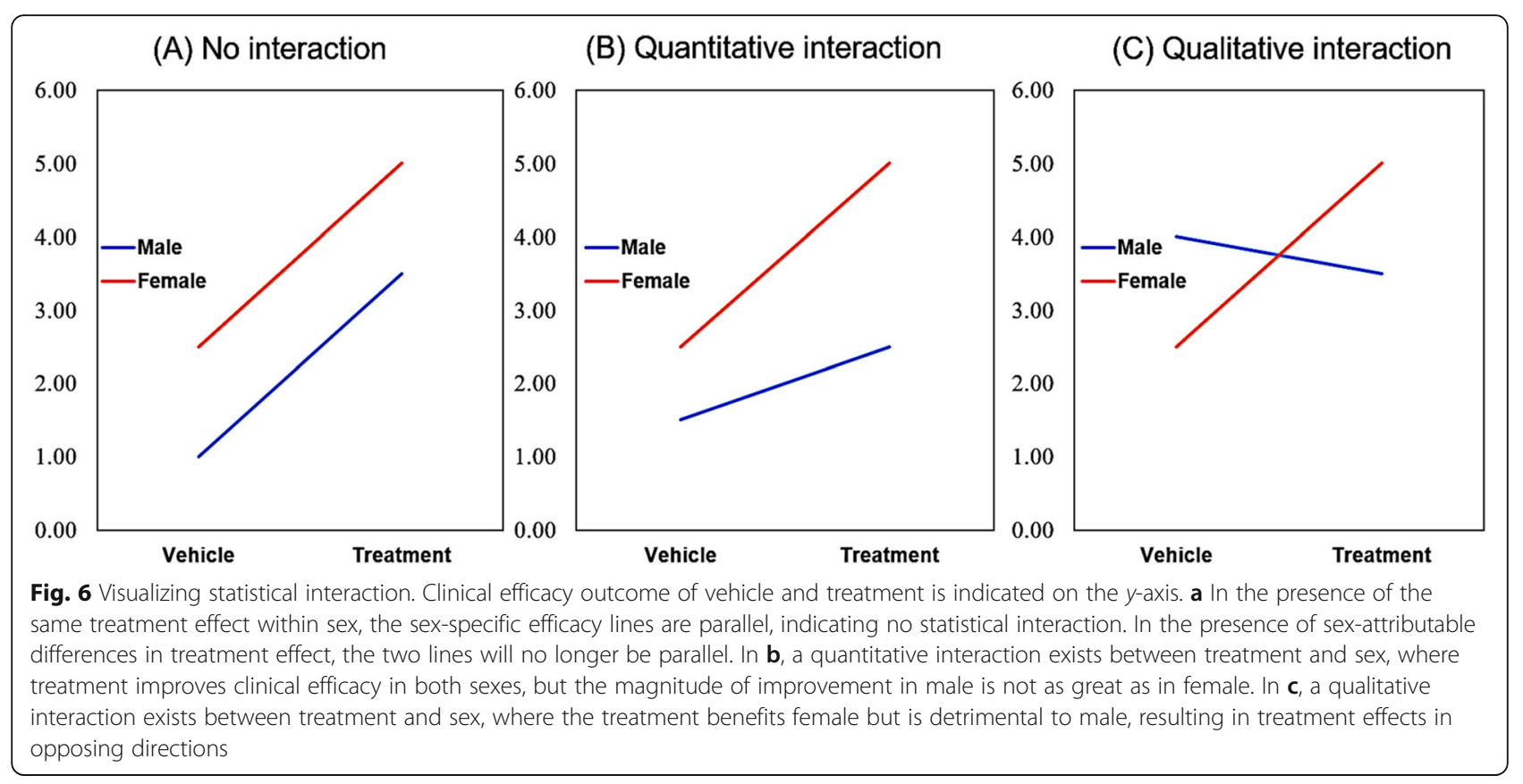

outcome (assume higher values correspond to better efficacy here) is plotted against treatment, for female and male separately. Two parallel lines indicate the absence of statistical interaction, while two non-parallel lines indicate some interaction exists between treatment and sex. Quantitative interaction (synonymously, non-crossover interaction) exists when treatments benefit both sexes, but with varying magnitude (here females show greater improvement with treatment than male). Qualitative interaction (synonymously cross-over interaction) [400] is present if treatment effects by sex trend in opposing directions (here, treatment is beneficial to female but harmful to male).

In retrospective studies, descriptive statistics can first be generated to summarize an efficacy outcome by combinations of treatment and sex, and sex-attributable effects can be visualized using appropriate plots (Fig. 6). A linear model (or factorial Analysis of Variance (ANOVA) in a balanced design) for a quantitative outcome, a logistic model for a binary outcome, or a Cox proportional hazard model for a survival outcome, can be applied to model the main effects and the interaction effect. The point estimates of treatment efficacy difference between sexes can be estimated, accompanied with $95 \%$ confidence interval, though the analysis results are usually regarded as exploratory and are used to generate new hypotheses to prospectively test the existence of a specific type of interaction.

In prospectively designed study on the interaction, we usually conduct two-sided hypothesis testing where an alternative hypothesis $\left(H_{1}\right)$ of unequal treatment efficacy between sexes is tested against a null hypothesis $\left(H_{0}\right)$ of equal treatment effect. In other words, we test on a nonzero difference in treatment efficacy against a zero difference between male and female. Let $\delta_{F}$ and $\delta_{M}$ denote the efficacy difference of treatment versus vehicle in female and male, respectively. The two-sided hypothesis testing can be mathematically written as,

$$
H_{0}: \delta_{F}-\delta_{M}=0 \text { versus } H_{1}: \delta_{M}-\delta_{M} \neq 0 .
$$

Depending on how treatment efficacy is measured, the efficacy difference $\delta$ can denote the arithmetic difference in the mean efficacy between treatment and vehicle for a quantitatively measured efficacy outcome (Fig. 6), or the odds ratio in logarithm scale for a binary outcome (namely, $\delta_{F}$ and $\delta_{M}$ representing log odds for response in female and male, respectively), or the relative risk (hazard ratio) in logarithm scale for a survival outcome (with $\delta_{F}$ and $\delta_{M}$ representing $\log$ hazard for survival in female and male, respectively). For a continuous treatment efficacy outcome $Y$, the sex attributable treatment efficacy difference can be written as,

$$
\delta_{F}-\delta_{M}=\left(\bar{Y}_{\text {Treatment }}^{\text {female }}-\bar{Y}_{\text {Vehicle }}^{\text {female }}\right)-\left(\bar{Y}_{\text {Treatment }}^{\text {male }}-\bar{Y}_{\text {Vehicle }}^{\text {male }}\right)
$$

with $\bar{Y}$ denoting the mean treatment efficacy under a treatment for a specific sex, as labeled. The treatment efficacy difference can be estimated and tested against zero by fitting a linear model with the main effects of treatment, sex, and the interaction. 
For two-sided hypothesis testing on a qualitative interaction, we specifically test on the presence of opposing directions against the same direction, namely,

$H_{0}:\left(\delta_{F}>0\right.$ and $\left.\delta_{M}>0\right)$ or $\left(\delta_{F}<0\right.$ and $\left.\delta_{M}<0\right)$

versus $H_{1}:\left(\delta_{F}>0\right.$ and $\left.\delta_{M}<0\right)$ or $\left(\delta_{F}<0\right.$ and $\left.\delta_{M}>0\right)$

A chi-square heterogeneity test on treatment effect can be used to test quantitative interaction, where the point estimates and standard errors for treatment difference (e.g., hazard ratio or odds ratio) in each sex are estimated and a test statistic is subsequently constructed using Equation (5) and (6) in Gail and Simon [400]. A Gail-Simon likelihood ratio test (GS LR test) can be used to perform specific testing on the presence of a qualitative interaction (using Equation (3a) and (3b) in Gail and Simon [400]) for both a two-sided and a one-sided test. A range test [401] has also been proposed for testing qualitative interaction, which has been reported to have similar power as the GS LR test [400] when only two subgroups (e.g., male and female) are involved.

Sample size needs to be pre-calculated for a prospective study to ensure sufficient power detecting the interaction. For a quantitative outcome, using the sample size equation for normal distribution [402], the total sample size of the study needed to detect the interaction with a type I error rate of $\alpha$ and type II error rate of $\beta$ (i.e., power $=1-\beta$ ) can be approximated by,

$$
n=\frac{16^{2}\left(Z_{1-\beta}+Z_{1-\alpha / 2}\right)}{\left(\delta_{F}-\delta_{M}\right)^{2}}
$$

with $Z$ indicating normal quantiles and $\sigma^{2}$ for the variance of the outcome, and thus $n / 4$ for each of the four groups by the combination of treatment and sex. For detecting an interaction between two binary factors in logistic regression for a binary outcome, an online app can be utilized (https://www. dartmouth.edu/ eugened/power-samplesize.php), by specifying the frequencies of outcome, treatment and sex, and the main effect odds ratios of treatment and sex for the binary outcome, as well as the interaction odds ratio [403]. For detecting an interaction between two correlated binary factors in the Cox proportional hazard model for a survival outcome, Equation (6) in Schmoor, et al. [404] can be employed to calculate the sample size; this has been implemented in the R package "powerSurvEpi” (http://CRAN.R-project.org/ package=powerSurvEpi), involving the four groups' prevalence and the hazard ratio of the interaction term. For testing the qualitative interaction using either the GS LR test or the range test, no closed form equation can be used to derive the sample size, and thus simulations have to be used to justify sample size.

Above, we have provided a very brief overview of the statistically relevant issues, focusing on the interaction between two binary factors (treatment and sex). Other methods and test statistics have been proposed in the literature for additional situations, such as treatment interacting with a continuous factor, or more complex, multiple factor interactions.

\section{Perspectives and significance}

Sexual differentiation typically results in two normal and distinct body morphologies and supporting physiologies. This is required for the sex-specific reproductive roles of males and females. The resultant sexual dimorphisms encompass genetic, epigenetic, and metabolic mechanisms at the cellular level, as well as systemic effects on every body system. Consequently, normal growth and aging differ in males and females, as does risk and severity of multiple diseases. Cancer is among those diseases with significant sex differences in risk, treatment response, and outcome. It is imperative that we incorporate the potential for sex differences to significantly impact on the cell and systems biology of cancer. Further, we must accept that these sex differences in cancer biology will affect how males and females respond to therapy, be it standard cytotoxic chemo- and radiationtherapies, immunotherapy, metabolic therapies, or targeted agents. It is essential that our laboratory and clinical research be appropriately powered and analyzed to detect sex effects. Similarly, as the implications of gender identity on health and disease become better defined, these should also be included in paradigms for oncology research and treatment. This is the only way that we can hope to follow through on the promise of precision medicine, to provide the very best care for each and every individual affected by cancer.

\section{Abbreviations}

GBM: Glioblastoma; BNST/POA: Bed nucleus of the stria terminalis/preoptic area; DNMTs: DNA methyltransferases; eNSCs: Embryonic neural stem cells;

IDH: Isocitrate dehydrogenase; iPSCs: Induced pluripotent stem cells; HDACs: Histone deacetylases; IncRNA: Long non-coding RNA; XIC: X inactivation center; XCl: X-chromosome inactivation; LOF: Loss of function; miRNAs: MicroRNAs; a-KG: a-ketoglutarate; 2-HG: 2-hydroxyglutarate; ROS: Reactive oxygen species; OGT: O-Linked N-acetylglucosamine transferase; GIcNAc: N-acetylglucosamine; TCA cycle: Tricarboxylic acid cycle; G6PD: Glucose-6-phosphate dehydrogenase; EZH2: Enhancer of zeste-2; DCA: Dichloroacetate; RB: Retinoblastoma protein; EMT: Epithelial to mesenchymal transition; OPC: Oligodendrocyte precursor cells; SVZ: Subventricular zone; LFS: Li-Fraumeni syndrome; NF1: Neurofibromin; CRISPR: Clustered regularly interspaced short palindromic repeats; Cas9: CRISPR-associated protein 9; CNS: Central nervous system; Mdm2: Mouse double minute 2 homolog; SASP: Senescence-associated secretory phenotype; CYP450: Cytochrome-P450; UGT: UDPglucuronosyltransferase; DDR: DNA-damage response; VSMC: Vascular smooth muscle cells; TIS: Therapy-induced senescence; MDSC: Myeloidderived suppressor cells; APCs: Antigen-presenting cells; B7-H1: B7-homolog 1; Treg: T regulatory cell; HCC: Hepatocellular carcinoma;

DEN: Diethylnitrosamine; KC: Kupffer cells; DCs: Dendritic cells; PDCs: Plasmacytoid DCs; ICls: Immune checkpoint inhibitors; PD-

1: Programmed cell death receptor 1; CTLA-4: Cytotoxic T-lymphocyteassociated protein 4; PD-L1: PD-1 ligand; ANOVA: Analysis of Variance;

LR: Likelihood ratio; GS LR test: Gail-Simon likelihood ratio test; WT: Wildtype; SEER: Surveillance, Epidemiology, and End Results; ECs: Endothelial cells;

EPCs: Endothelial progenitor cells; VEGFs: Vascular endothelial growth factors; 
FGFs: Fibroblast growth factors; PDGFs: Platelet-derived growth factors; MMPs: Matrix metalloproteases; VEGFR2: VEGF receptor-2; eNOS: Endothelial nitric oxide synthase; HUVECs: Human umbilical endothelial cells; PECAM1: Platelet-endothelial cell adhesion molecule 1; ER: Estrogen receptor; PR: Progesterone receptor; AR: Androgen receptor; E2: Estradiol; EGF: Epidermal growth factor; IGF-1: Insulin growth factor-1; PDGF: Plateletderived growth factor; PAD: Peripheral artery disease; BCAAs: Branched-chain amino acids; HK-1: Hexokinase-1; PFK-1: Phosphofructokinase-1; PK-1/ 2: Pyruvate kinase-1/2; PPP: Pentose phosphate pathway

\section{Authors' contributions}

JSL-Overview of sex differences in cancer, LB-Epigenetics, JS-Metabolism, NR-p53, GR-Cellular senescence, SFR and RSK - Immunity, SC and PI—Angiogenesis, JL-Statistical considerations, JBR-overall organization, writing, and editing. All authors read and approved the final manuscript.

\section{Funding}

Work in the Rubin Lab is supported by NIH, R01 CA174737 (JBR), The Children's Discovery Institute of Washington University (JBR), Prayers for Maria Foundation (JBR), St Louis Children's Hospital Foundation (JBR), BarnesJewish Hospital Foundation (JBR), Barnard Research Funds (JBR), Joshua's Great Things Foundation (JBR). Work in the Klein lab is supported by NIH grants U19 Al083019 (RSK), R01 NS052632 (RSK), and R01 Al101400 (RSK) and National Society of Multiple Sclerosis (RSK). Work in the Imoukhuede Lab is supported by National Science Foundation 1653925 (PI) and the American Heart Association 16SDG26940002 (PI).

\section{Availability of data and materials}

Not applicable

\section{Ethics approval and consent to participate}

Not applicable

\section{Consent for publication}

Not applicable

\section{Competing interests}

The authors report that they have no competing interests.

\section{Author details}

'Department of Pediatrics, Washington University School of Medicine, 660 South Euclid Avenue, St Louis, MO 63110, USA. ²Department of Neuroscience, Washington University School of Medicine, 660 South Euclid Avenue, St Louis, MO 63110, USA. ${ }^{3}$ Department of Medicine, Washington University School of Medicine, 660 South Euclid Avenue, St Louis, MO 63110, USA. ${ }^{4}$ Department of Biomedical Engineering, Washington University School of Medicine, 660 South Euclid Avenue, St Louis, MO 63110, USA. ${ }^{5}$ Department of Surgery, Washington University School of Medicine, 660 South Euclid Avenue, St Louis, MO 63110, USA.

Received: 29 September 2019 Accepted: 18 March 2020 Published online: 15 April 2020

\section{References}

1. Cook MB, McGlynn KA, Devesa SS, Freedman ND, Anderson WF. Sex disparities in cancer mortality and survival. Cancer epidemiology, biomarkers \& prevention : a publication of the American Association for Cancer Research, cosponsored by the American Society of Preventive Oncology. 2011;20:1629-37. https://doi.org/10.1158/1055-9965.EPI-11-0246.

2. Siegel RL, Miller KD, Jemal A. Cancer Statistics, 2017. CA Cancer J Clin. 2017; 67:7-30. https://doi.org/10.3322/caac.21387.

3. Conforti $F$, et al. Cancer immunotherapy efficacy and patients' sex: a systematic review and meta-analysis. Lancet Oncol. 2018;19:737-46. https:// doi.org/10.1016/S1470-2045(18)30261-4

4. Rampen FH. Malignant melanoma: sex differences in response to chemotherapy? Eur J Cancer Clin Oncol. 1982;18:107-10.

5. Siegel RL, Miller KD, Jemal A. Cancer statistics, 2016. CA Cancer J Clin. 2016; 66:7-30. https://doi.org/10.3322/caac.21332.
6. Mervic L. Time course and pattern of metastasis of cutaneous melanoma differ between men and women. PLoS One. 2012;7:e32955. https://doi.org/ 10.1371/journal.pone.0032955.

7. Pal SK, Hurria A. Impact of age, sex, and comorbidity on cancer therapy and disease progression. J Clin Oncol. 2010;28:4086-93. https://doi.org/10.1200/ JCO.2009.27.0579.

8. Rampen F. Malignant melanoma: sex differences in survival after evidence of distant metastasis. Br J Cancer. 1980;42:52-7. https://doi.org/10.1038/bjc. 1980.202.

9. Heinlein $C A$, Chang C. Androgen receptor in prostate cancer. Endocr Rev. 2004;25:276-308. https://doi.org/10.1210/er.2002-0032.

10. Weiss JR, Moysich KB, Swede H. Epidemiology of male breast cancer. Cancer epidemiology, biomarkers \& prevention : a publication of the American Association for Cancer Research, cosponsored by the American Society of Preventive Oncology. 2005;14:20-6.

11. Yager JD, Davidson NE. Estrogen carcinogenesis in breast cancer. N Engl J Med. 2006:354:270-82. https://doi.org/10.1056/NEJMra050776.

12. Allavena P, Garlanda C, Borrello MG, Sica A, Mantovani A. Pathways connecting inflammation and cancer. Curr Opin Genet Dev. 2008;18:3-10. https://doi.org/10.1016/j.gde.2008.01.003.

13. Antoni $\mathrm{S}$, et al. Bladder cancer incidence and mortality: a global overview and recent trends. Eur Urol. 2017;71:96-108. https://doi.org/10.1016/j.eururo. 2016.06.010.

14. Aron M, Nguyen MM, Stein RJ, Gill IS. Impact of gender in renal cell carcinoma: an analysis of the SEER database. Eur Urol. 2008:54:133-40. https://doi.org/10.1016/j.eururo.2007.12.001.

15. Brenner $\mathrm{H}$, Rothenbacher $\mathrm{D}$, Arndt $\mathrm{V}$. Epidemiology of stomach cancer. Methods Mol Biol. 2009:472:467-77. https://doi.org/10.1007/978-1-60327492-0_23.

16. Cartwright RA, Gurney KA, Moorman AV. Sex ratios and the risks of haematological malignancies. Br J Haematol. 2002;118:1071-7. https://doi. org/10.1046/j.1365-2141.2002.03750.x.

17. Chow WH, et al. Risk factors for small intestine cancer. Cancer Causes Control. 1993:4:163-9.

18. Cook MB, Chow WH, Devesa SS. Oesophageal cancer incidence in the United States by race, sex, and histologic type, 1977-2005. Br J Cancer. 2009; 101:855-9. https://doi.org/10.1038/sj.bjc.6605246.

19. Farahati, J., Bucsky, P., Parlowsky, T., Mader, U. \& Reiners, C. Characteristics of differentiated thyroid carcinoma in children and adolescents with respect to age, gender, and histology. Cancer 80, 2156-2162, doi:10.1002/(sici)10970142(19971201)80:11 < 2156::aid-cncr16 > 3.0.c0;2-y (1997).

20. Jawad MU, et al. Ewing sarcoma demonstrates racial disparities in incidence-related and sex-related differences in outcome: an analysis of 1631 cases from the SEER database, 1973-2005. Cancer. 2009;115:3526-36. https://doi.org/10.1002/cncr.24388.

21. Kfoury N, et al. Cooperative p16 and p21 action protects female astrocytes from transformation. Acta Neuropathol Commun. 2018;6:12. https://doi.org/ 10.1186/s40478-018-0513-5.

22. Kim SE, et al. Sex- and gender-specific disparities in colorectal cancer risk World J Gastroenterol. 2015;21:5167-75. https://doi.org/10.3748/wjg.v21.i17. 5167.

23. Lautrup, M. D. et al. Male breast cancer: a nation-wide population-based comparison with female breast cancer. Acta Oncol 57, 613-621, doi:10.1080/ 0284186X.2017.1418088 (2018)

24. Li Y, Izumi $\mathrm{K}$, Miyamoto $\mathrm{H}$. The role of the androgen receptor in the development and progression of bladder cancer. Jpn J Clin Oncol. 2012;42: 569-77. https://doi.org/10.1093/jjco/hys072.

25. Muscat, JE. \& Wynder, EL. Tobacco, alcohol, asbestos, and occupational risk factors for laryngeal cancer. Cancer 69, 2244-2251, doi:10.1002/10970142(19920501)69:9 < 2244:"aid-cncr2820690906 > 3.0.c0:2-o (1992).

26. Muscat JE, Wynder EL. A case/control study of risk factors for major salivary gland cancer. Otolaryngol Head Neck Surg. 1998;118:195-8. https:/doi.org/ 10.1016/S0194-5998(98)80013-2.

27. Naugler WE, et al. Gender disparity in liver cancer due to sex differences in MyD88-dependent IL-6 production. Science. 2007;317:121-4. https://doi.org/ $10.1126 /$ science. 1140485 .

28. Nosrati A, Wei ML. Sex disparities in melanoma outcomes: the role of biology. Arch Biochem Biophys. 2014;563:42-50. https://doi.org/10.1016/j. abb.2014.06.018

29. Patel JD. Lung cancer in women. J Clin Oncol. 2005:23:3212-8. https://doi. org/10.1200/JCO.2005.11.486. 
30. Polednak, AP. \& Flannery, JT. Brain, other central nervous system, and eye cancer. Cancer 75, 330-337, doi:10.1002/1097-0142(19950101)75:1 + <330: aid-cncr2820751315 > 3.0.co;2-5 (1995).

31. Prieto J. Inflammation, HCC and sex: IL-6 in the centre of the triangle. J Hepatol. 2008;48:380-1. https://doi.org/10.1016/j.jhep.2007.11.007.

32. Rahbari $R$, Zhang L, Kebebew E. Thyroid cancer gender disparity. Future Oncol. 2010;6:1771-9. https://doi.org/10.2217/fon.10.127.

33. Sharma A, Sharma KL, Gupta A, Yadav A, Kumar A. Gallbladder cancer epidemiology, pathogenesis and molecular genetics: recent update. World J Gastroenterol. 2017;23:3978-98. https://doi.org/10.3748/wjg.v23.i22.3978.

34. Soderlund $\mathrm{S}$, et al. Inflammatory bowel disease confers a lower risk of colorectal cancer to females than to males. Gastroenterology. 2010;138: 1697-703. https://doi.org/10.1053/j.gastro.2010.02.007.

35. Sun T, et al. Sexually dimorphic RB inactivation underlies mesenchymal glioblastoma prevalence in males. J Clin Invest. 2014;124:4123-33. https:// doi.org/10.1172/JCI71048.

36. Sun T, Warrington NM, Rubin JB. Why does Jack, and not Jill, break his crown? Sex disparity in brain tumors. Biol Sex Differ. 2012;3:3.

37. Swango PA. Cancers of the oral cavity and pharynx in the United States: an epidemiologic overview. J Public Health Dent. 1996;56:309-18.

38. Tota JE, et al. Rising incidence of oral tongue cancer among white men and women in the United States, 1973-2012. Oral Oncol. 2017;67:146-52. https:// doi.org/10.1016/j.oraloncology.2017.02.019.

39. Tseng HF, Morgenstern H, Mack TM, Peters RK. Risk factors for anal cancer: results of a population-based case--control study. Cancer Causes Control. 2003; 14:837-46

40. Warrington NM, et al. The cyclic AMP pathway is a sex-specific modifier of glioma risk in type I neurofibromatosis patients. Cancer Res. 2015;75:16-21. https://doi.org/10.1158/0008-5472.CAN-14-1891.

41. Yadav D, Lowenfels AB. The epidemiology of pancreatitis and pancreatic cancer. Gastroenterology. 2013;144:1252-61. https://doi.org/10.1053/j.gastro. 2013.01.068

42. Yan TD, Popa E, Brun EA, Cerruto CA, Sugarbaker PH. Sex difference in diffuse malignant peritoneal mesothelioma. Br J Surg. 2006;93:1536-42. https://doi.org/10.1002/bjs.5377.

43. Curtin, SC., Minino, AM. \& Anderson, RN. Declines in cancer death rates among children and adolescents in the United States, 1999-2014. NCHS Data Brief, 1-8 (2016).

44. Centers for Disease Control and Prevention, N. C. f. H. S. WHO Growth Standards Are Recommended for Use in the U.S. for Infants and Children 0 to 2 Years of Age, <https://www.cdc.gov/growthcharts/who_ charts.htm> (2010).

45. Perrin JS, et al. Sex differences in the growth of white matter during adolescence. Neuroimage. 2009:45:1055-66. https://doi.org/10.1016/j. neuroimage.2009.01.023.

46. Jaillon S, Berthenet K, Garlanda C. Sexual dimorphism in innate immunity. Clin Rev Allergy Immunol. 2019;56:308-21. https://doi.org/10.1007/s12016017-8648-x.

47. Klein SL, Flanagan KL. Sex differences in immune responses. Nat Rev Immunol. 2016;16:626-38. https://doi.org/10.1038/nri.2016.90.

48. Chaudhari $\mathrm{S}$, et al. Mechanisms of sex disparities in cardiovascular function and remodeling. Compr Physiol. 2018;9:375-411. https://doi.org/10.1002/ cphy.c180003.

49. Chella Krishnan, K., Mehrabian, M. \& Lusis, AJ. Sex differences in metabolism and cardiometabolic disorders. Curr Opin Lipidol 29, 404-410, doi:10.1097/ MOL.0000000000000536 (2018).

50. Wilkinson HN, Hardman MJ. The role of estrogen in cutaneous ageing and repair. Maturitas. 2017;103:60-4. https://doi.org/10.1016/j.maturitas.2017.06.026.

51. Ostrom QT, et al. CBTRUS statistical report: primary brain and other central nervous system tumors diagnosed in the United States in 2012-2016. Neuro Oncol. 2019;21:v1-v100. https://doi.org/10.1093/neuonc/noz150.

52. Franceschi $E$, et al. The prognostic roles of gender and O6-methylguanineDNA methyltransferase methylation status in glioblastoma patients: the female power. World Neurosurg. 2018;112:e342-7. https://doi.org/10.1016/j. wneu.2018.01.045

53. Gittleman $\mathrm{H}$, et al. Sex is an important prognostic factor for glioblastoma but not for nonglioblastoma. Neurooncol Pract. 2019;6:451-62. https://doi. org/10.1093/nop/npz019.

54. Ostrom QT, et al. Sex-specific gene and pathway modeling of inherited glioma risk. Neuro Oncol. 2019;21:71-82. https://doi.org/10.1093/neuonc/ noy 135.
55. Ostrom QT, Rubin JB, Lathia JD, Berens ME, Barnholtz-Sloan JS. Females have the survival advantage in glioblastoma. Neuro Oncol. 2018;20:576-7. https://doi.org/10.1093/neuonc/noy002.

56. Schiffgens, S. et al. Sex-specific clinicopathological significance of novel (Frizzled-7) and established (MGMT, IDH1) biomarkers in glioblastoma. Oncotarget 7, 55169-55180, doi:10.18632/oncotarget.10465 (2016).

57. Silvestris DA, et al. Dynamic inosinome profiles reveal novel patient stratification and gender-specific differences in glioblastoma. Genome Biol. 2019;20:33. https://doi.org/10.1186/s13059-019-1647-x.

58. Tian, M. et al. Impact of gender on the survival of patients with glioblastoma. Biosci Rep 38, doi:10.1042/BSR20180752 (2018).

59. Yang, W. et al. Sex differences in GBM revealed by analysis of patient imaging, transcriptome, and survival data. Sci Transl Med 11, doi:10.1126/ scitranslmed.aao5253 (2019)

60. Brennan CW, et al. The somatic genomic landscape of glioblastoma. Cell. 2013;155:462-77. https://doi.org/10.1016/j.cell.2013.09.034.

61. Dawson MA, Kouzarides T. Cancer epigenetics: from mechanism to therapy. Cell. 2012;150:12-27. https://doi.org/10.1016/j.cell.2012.06.013.

62. Feinberg AP, Koldobskiy MA, Gondor A. Epigenetic modulators, modifiers and mediators in cancer aetiology and progression. Nat Rev Genet. 2016;17: 284-99. https://doi.org/10.1038/nrg.2016.13.

63. Mack SC, Hubert CG, Miller TE, Taylor MD, Rich JN. An epigenetic gateway to brain tumor cell identity. Nat Neurosci. 2016;19:10-9. https://doi.org/10. 1038/nn.4190

64. Sturm D, et al. Hotspot mutations in H3F3A and IDH1 define distinct epigenetic and biological subgroups of glioblastoma. Cancer Cell. 2012;22: 425-37. https://doi.org/10.1016/j.ccr.2012.08.024.

65. Waddington $\mathrm{CH}$. Canalization of development and genetic assimilation of acquired characters. Nature. 1959;183:1654-5. https://doi.org/10.1038/ $1831654 a 0$.

66. Flavahan, WA., Gaskell, E. \& Bernstein, BE. Epigenetic plasticity and the hallmarks of cancer. Science 357, doi:10.1126/science.aal2380 (2017).

67. Suva ML, Riggi N, Bernstein BE. Epigenetic reprogramming in cancer. Science. 2013;339:1567-70. https://doi.org/10.1126/science.1230184.

68. Liau, BB. et al. Adaptive chromatin remodeling drives glioblastoma stem cell plasticity and drug tolerance. Cell Stem Cell 20, 233-246 e237, doi:10.1016/j. stem.2016.11.003 (2017).

69. Roesch $\mathrm{A}$, et al. Overcoming intrinsic multidrug resistance in melanoma by blocking the mitochondrial respiratory chain of slow-cycling JARID1B(high) cells. Cancer Cell. 2013;23:811-25. https://doi.org/10.1016/ j.ccr.2013.05.003.

70. Sharma SV, et al. A chromatin-mediated reversible drug-tolerant state in cancer cell subpopulations. Cell. 2010;141:69-80. https://doi.org/10.1016/j. cell.2010.02.027.

71. Banelli $B$, et al. The histone demethylase KDM5A is a key factor for the resistance to temozolomide in glioblastoma. Cell Cycle. 2015;14:3418-29. https://doi.org/10.1080/15384101.2015.1090063.

72. Banelli, B. et al. Small molecules targeting histone demethylase genes (KDMs) inhibit growth of temozolomide-resistant glioblastoma cells. Oncotarget 8, 34896-34910, doi:10.18632/oncotarget.16820 (2017)

73. Jones PA, Issa JP, Baylin S. Targeting the cancer epigenome for therapy. Nat Rev Genet. 2016;17:630-41. https://doi.org/10.1038/nrg.2016.93.

74. Liu J, Morgan M, Hutchison K, Calhoun VD. A study of the influence of sex on genome wide methylation. PLoS One. 2010;5:e10028. https://doi.org/10. 1371/journal.pone.0010028.

75. Maschietto $\mathrm{M}$, et al. Sex differences in DNA methylation of the cord blood are related to sex-bias psychiatric diseases. Sci Rep. 2017;7:44547. https://doi. org/10.1038/srep44547.

76. Singmann $\mathrm{P}$, et al. Characterization of whole-genome autosomal differences of DNA methylation between men and women. Epigenetics Chromatin. 2015;8:43. https://doi.org/10.1186/s13072-015-0035-3.

77. Yousefi $\mathrm{P}$, et al. Sex differences in DNA methylation assessed by $450 \mathrm{~K}$ BeadChip in newborns. BMC Genomics. 2015;16:911. https://doi.org/10. 1186/s12864-015-2034-y.

78. Martin $\mathrm{E}$, et al. Sexual epigenetic dimorphism in the human placenta: implications for susceptibility during the prenatal period. Epigenomics. 2017:9:267-78. https://doi.org/10.2217/epi-2016-0132.

79. Garcia-Calzon S, Perfilyev A, de Mello VD, Pihlajamaki J, Ling C. Sex differences in the methylome and transcriptome of the human liver and circulating HDL-cholesterol levels. J Clin Endocrinol Metab. 2018;103:4395408. https://doi.org/10.1210/jc.2018-00423. 
80. Grimm SA, et al. DNA methylation in mice is influenced by genetics as well as sex and life experience. Nat Commun. 2019;10:305. https://doi.org/10. 1038/s41467-018-08067-z.

81. McCormick $H$, et al. Isogenic mice exhibit sexually-dimorphic DNA methylation patterns across multiple tissues. BMC Genomics. 2017;18:966. https://doi.org/10.1186/s12864-017-4350-x.

82. Reizel Y, et al. Gender-specific postnatal demethylation and establishment of epigenetic memory. Genes Dev. 2015;29:923-33. https://doi.org/10.1101/ gad.259309.115

83. Hall $\mathrm{E}$, et al. Sex differences in the genome-wide DNA methylation pattern and impact on gene expression, microRNA levels and insulin secretion in human pancreatic islets. Genome Biol. 2014;15:522. https://doi.org/10.1186/ s13059-014-0522-z.

84. Davegardh C, et al. Sex influences DNA methylation and gene expression in human skeletal muscle myoblasts and myotubes. Stem Cell Res Ther. 2019; 10:26. https://doi.org/10.1186/s13287-018-1118-4.

85. Ghahramani NM, et al. The effects of perinatal testosterone exposure on the DNA methylome of the mouse brain are late-emerging. Biol Sex Differ. 2014;5:8. https://doi.org/10.1186/2042-6410-5-8.

86. Gross JA, et al. Characterizing 5-hydroxymethylcytosine in human prefrontal cortex at single base resolution. BMC Genomics. 2015;16:672. https://doi. org/10.1186/s12864-015-1875-8

87. Spiers H, Hannon E, Schalkwyk LC, Bray NJ, Mill J. 5-hydroxymethylcytosine is highly dynamic across human fetal brain development. BMC Genomics. 2017;18:738. https://doi.org/10.1186/s12864-017-4091-x.

88. Spiers $\mathrm{H}$, et al. Methylomic trajectories across human fetal brain development. Genome Res. 2015;25:338-52. https://doi.org/10.1101/gr. 180273.114.

89. $\mathrm{Xu} \mathrm{H}$, et al. Sex-biased methylome and transcriptome in human prefrontal cortex. Hum Mol Genet. 2014;23:1260-70. https://doi.org/10.1093/hmg/ddt516.

90. Shen $E Y$, et al. Epigenetics and sex differences in the brain: a genome-wide comparison of histone-3 lysine-4 trimethylation ( $\mathrm{H} 3 \mathrm{~K} 4 \mathrm{me} 3)$ in male and female mice. Exp Neurol. 2015;268:21-9. https://doi.org/10.1016/j.expneurol. 2014.08.006.

91. Tsai HW, Grant PA, Rissman EF. Sex differences in histone modifications in the neonatal mouse brain. Epigenetics. 2009;4:47-53. https://doi.org/10. 4161/epi.4.1.7288.

92. Arnold AP. The organizational-activational hypothesis as the foundation for a unified theory of sexual differentiation of all mammalian tissues. Horm Behav. 2009:55:570-8.

93. Phoenix CH, Goy RW, Gerall AA, Young WC. Organizing action of prenatally administered testosterone propionate on the tissues mediating mating behavior in the female guinea pig. Endocrinology. 1959;65:369-82. https:// doi.org/10.1210/endo-65-3-369.

94. Bramble MS, Lipson A, Vashist N, Vilain E. Effects of chromosomal sex and hormonal influences on shaping sex differences in brain and behavior: lessons from cases of disorders of sex development. J Neurosci Res. 2017;95: 65-74. https://doi.org/10.1002/jnr.23832

95. Lee PA, et al. Global disorders of sex development update since 2006: perceptions, approach and care. Horm Res Paediatr. 2016;85:158-80. https:// doi.org/10.1159/000442975.

96. Kolodkin MH, Auger AP. Sex difference in the expression of DNA methyltransferase $3 a$ in the rat amygdala during development. J Neuroendocrinol. 2011;23:577-83. https://doi.org/10.1111/j.1365-2826.2011. 02147.x.

97. Schwarz JM, Nugent BM, MCCarthy MM. Developmental and hormoneinduced epigenetic changes to estrogen and progesterone receptor genes in brain are dynamic across the life span. Endocrinology. 2010;151:4871-81. https://doi.org/10.1210/en.2010-0142.

98. Nugent $\mathrm{BM}$, et al. Brain feminization requires active repression of masculinization via DNA methylation. Nat Neurosci. 2015;18:690-7. https:// doi.org/10.1038/nn.3988

99. Mosley M, et al. Neonatal inhibition of DNA methylation alters cell phenotype in sexually dimorphic regions of the mouse brain Endocrinology. 2017;158:1838-48. https://doi.org/10.1210/en.2017-00205.

100. Bramble MS, et al. Sex-specific effects of testosterone on the sexually dimorphic transcriptome and epigenome of embryonic neural stem/ progenitor cells. Sci Rep. 2016:6:36916. https://doi.org/10.1038/srep36916.

101. Turcan S, et al. IDH1 mutation is sufficient to establish the glioma hypermethylator phenotype. Nature. 2012:483:479-83. https://doi.org/10. 1038/nature10866
102. Ehrlich M. DNA hypomethylation in cancer cells. Epigenomics. 2009;1:23959. https://doi.org/10.2217/epi.09.33.

103. Madakashira BP, Sadler KC. DNA methylation, nuclear organization, and cancer. Front Genet. 2017;8:76. https://doi.org/10.3389/fgene.2017. 00076.

104. Mikkelsen TS, et al. Dissecting direct reprogramming through integrative genomic analysis. Nature. 2008;454:49-55. https://doi.org/10.1038/ nature07056.

105. Matsuda Kl, et al. Histone deacetylation during brain development is essential for permanent masculinization of sexual behavior. Endocrinology. 2011;152:2760-7. https://doi.org/10.1210/en.2011-0193.

106. Murray EK, Hien A, de Vries GJ, Forger NG. Epigenetic control of sexual differentiation of the bed nucleus of the stria terminalis. Endocrinology. 2009;150:4241-7. https://doi.org/10.1210/en.2009-0458.

107. Bermejo-Alvarez P, Rizos D, Rath D, Lonergan P, Gutierrez-Adan A. Sex determines the expression level of one third of the actively expressed genes in bovine blastocysts. Proc Natl Acad Sci U S A. 2010;107:3394-9. https://doi.org/10.1073/pnas.0913843107.

108. Kobayashi S, et al. Comparison of gene expression in male and female mouse blastocysts revealed imprinting of the X-linked gene, Rhox5/Pem, at preimplantation stages. Curr Biol. 2006;16:166-72. https://doi.org/10.1016/j. cub.2005.11.071

109. Lowe R, Gemma C, Rakyan VK, Holland ML. Sexually dimorphic gene expression emerges with embryonic genome activation and is dynamic throughout development. BMC Genomics. 2015;16:295. https://doi.org/10. 1186/s12864-015-1506-4.

110. Werner RJ, et al. Sex chromosomes drive gene expression and regulatory dimorphisms in mouse embryonic stem cells. Biol Sex Differ. 2017;8:28. https://doi.org/10.1186/s13293-017-0150-x.

111. Zylicz, JJ. et al. The implication of early chromatin changes in $X$ chromosome inactivation. Cell 176, 182-197 e123, doi:10.1016/j.cell.2018.11. 041 (2019).

112. Pasque $\mathrm{V}$, et al. $\mathrm{X}$ chromosome reactivation dynamics reveal stages of reprogramming to pluripotency. Cell. 2014;159:1681-97. https://doi.org/10. 1016/j.cell.2014.11.040.

113. Cantone, I. \& Fisher, AG. Human X chromosome inactivation and reactivation: implications for cell reprogramming and disease. Philos Trans $R$ Soc Lond B Biol Sci 372, doi:10.1098/rstb.2016.0358 (2017).

114. Dandulakis MG, Meganathan K, Kroll KL, Bonni A, Constantino JN. Complexities of $X$ chromosome inactivation status in female human induced pluripotent stem cells-a brief review and scientific update for autism research. J Neurodev Disord. 2016;8:22. https://doi.org/10.1186/ s1 1689-016-9155-8.

115. Di KQ, et al. Generation of fully pluripotent female murine-induced pluripotent stem cells. Biol Reprod. 2015;92:123. https://doi.org/10.1095/ biolreprod.114.124958

116. Chaligne R, Heard E. X-chromosome inactivation in development and cancer. FEBS Lett. 2014;588:2514-22. https://doi.org/10.1016/j.febslet.2014.06.023.

117. Pageau GJ, Hall LL, Ganesan S, Livingston DM, Lawrence JB. The disappearing Barr body in breast and ovarian cancers. Nat Rev Cancer. 2007; 7:628-33. https://doi.org/10.1038/nrc2172.

118. Yang Z, Jiang $X$, Jiang $X$, Zhao $H$. X-inactive-specific transcript: a long noncoding RNA with complex roles in human cancers. Gene. 2018;679:2835. https://doi.org/10.1016/j.gene.2018.08.071.

119. Liu, JL., Zhang, WQ., Zhao, M. \& Huang, M.Y. Upregulation of long noncoding RNA XIST is associated with poor prognosis in human cancers. J Cell Physiol 234, 6594-6600, doi:https://doi.org/10.1002/jcp.27400 (2019).

120. Zhu J, Kong F, Xing L, Jin Z, Li Z. Prognostic and clinicopathological value of long noncoding RNA XIST in cancer. Clin Chim Acta. 2018;479:43-7. https://doi.org/10.1016/j.cca.2018.01.005.

121. Liu F, et al. Long noncoding RNA FTX inhibits hepatocellular carcinoma proliferation and metastasis by binding MCM2 and miR-374a. Oncogene. 2016;35:5422-34. https://doi.org/10.1038/onc.2016.80.

122. Jin $\mathrm{M}$, et al. Long noncoding RNA JPX correlates with poor prognosis and tumor progression in non-small cell lung cancer by interacting with miR-1455p and CCND2. Carcinogenesis. 2019. https://doi.org/10.1093/carcin/bgz125.

123. Yang $F$, et al. Identifying potential metastasis-related long non-coding RNAs, microRNAs, and message RNAs in the esophageal squamous cell carcinoma. J Cell Biochem. 2019;120:13202-15. https://doi.org/10.1002/jcb.28594.

124. Jiang $S$, et al. An expanded landscape of human long noncoding RNA. Nucleic Acids Res. 2019;47:7842-56. https://doi.org/10.1093/nar/gkz621. 
125. Liu S, et al. Annotation and cluster analysis of spatiotemporal- and sexrelated IncRNA expression in rhesus macaque brain. Genome Res. 2017;27: 1608-20. https://doi.org/10.1101/gr.217463.116.

126. Khalil AM, et al. Many human large intergenic noncoding RNAs associate with chromatin-modifying complexes and affect gene expression. Proc Natl Acad Sci U S A. 2009;106:11667-72. https://doi.org/10.1073/pnas. 0904715106

127. Bhan A, Soleimani M, Mandal SS. Long noncoding RNA and cancer: a new paradigm. Cancer Res. 2017;77:3965-81. https://doi.org/10.1158/0008-5472 CAN-16-2634.

128. Chiu, HS. et al. Pan-cancer analysis of IncRNA regulation supports their targeting of cancer genes in each tumor context. Cell Rep 23, 297-312 e212, doi:10.1016/j.celrep.2018.03.064 (2018)

129. Balas MM, Johnson AM. Exploring the mechanisms behind long noncoding RNAs and cancer. Noncoding RNA Res. 2018;3:108-17. https://doi.org/10. 1016/j.ncrna.2018.03.001.

130. Chi, Y., Wang, D., Wang, J., Yu, W. \& Yang, J. Long non-coding RNA in the pathogenesis of cancers. Cells 8, doi:10.3390/cells8091015 (2019).

131. Slack FJ, Chinnaiyan AM. The role of non-coding RNAs in oncology. Cell. 2019;179:1033-55. https://doi.org/10.1016/j.cell.2019.10.017.

132. Lee JT, Bartolomei MS. X-inactivation, imprinting, and long noncoding RNAs in health and disease. Cell. 2013;152:1308-23. https://doi.org/10.1016/j.cell. 2013.02.016

133. Gregg C, Zhang J, Butler JE, Haig D, Dulac C. Sex-specific parent-of-origin allelic expression in the mouse brain. Science. 2010;329:682-5. https://doi. org/10.1126/science.1190831.

134. Lepage JF, et al. Genomic imprinting effects of the $X$ chromosome on brain morphology. J Neurosci. 2013;33:8567-74. https://doi.org/10.1523/ JNEUROSCI.5810-12.2013

135. Carrel L, Willard HF. X-inactivation profile reveals extensive variability in $X$ linked gene expression in females. Nature. 2005;434:400-4. https://doi.org/ 10.1038/nature03479.

136. Yang F, Babak T, Shendure J, Disteche CM. Global survey of escape from X inactivation by RNA-sequencing in mouse. Genome Res. 2010;20:614-22. https://doi.org/10.1101/gr.103200.109.

137. Wijchers PJ, et al. Sexual dimorphism in mammalian autosomal gene regulation is determined not only by Sry but by sex chromosome complement as well. Dev Cell. 2010;19:477-84. https://doi.org/10.1016/j. devcel.2010.08.005.

138. Wijchers PJ, Festenstein RJ. Epigenetic regulation of autosomal gene expression by sex chromosomes. Trends Genet. 2011;27:132-40. https://doi. org/10.1016/j.tig.2011.01.004

139. Lan $\mathrm{F}$, et al. A histone $\mathrm{H} 3$ lysine 27 demethylase regulates animal posterior development. Nature. 2007:449:689-94. https://doi.org/10.1038/nature06192.

140. Snell DM, Turner JM. A. Sex chromosome effects on male-female differences in mammals. Curr Biol. 2018;28:R1313-24. https://doi.org/10.1016/j.cub.2018.09.018,

141. Xu J, Deng X, Watkins R, Disteche CM. Sex-specific differences in expression of histone demethylases Utx and Uty in mouse brain and neurons. J Neurosci. 2008;28:4521-7. https://doi.org/10.1523/JNEUROSCI.5382-07.2008

142. Dunford A, et al. Tumor-suppressor genes that escape from X-inactivation contribute to cancer sex bias. Nat Genet. 2017:49:10-6. https://doi.org/10. 1038/ng.3726

143. Kaneko, S. \& Li, X. X chromosome protects against bladder cancer in females via a KDM6A-dependent epigenetic mechanism. Sci Adv 4, eaar5598, doi:10.1126/sciadv.aar5598 (2018)

144. Li X, et al. UTX is an escape from X-inactivation tumor-suppressor in B cell lymphoma. Nat Commun. 2018;9:2720. https://doi.org/10.1038/s41467-01805084-w.

145. Van der Meulen J, et al. The H3K27me3 demethylase UTX is a genderspecific tumor suppressor in T-cell acute lymphoblastic leukemia. Blood. 2015;125:13-21. https://doi.org/10.1182/blood-2014-05-577270.

146. Andricovich, J. et al. Loss of KDM6A activates super-enhancers to induce gender-specific squamous-like pancreatic cancer and confers sensitivity to BET inhibitors. Cancer Cell 33, 512-526 e518, doi:10.1016/j. ccell.2018.02.003 (2018)

147. Reinius $B$, et al. Female-biased expression of long non-coding RNAs in domains that escape X-inactivation in mouse. BMC Genomics. 2010;11:614. https://doi.org/10.1186/1471-2164-11-614.

148. Care A, et al. Sex disparity in cancer: roles of microRNAs and related functional players. Cell Death Differ. 2018:25:477-85. https://doi.org/10.1038/ s41418-017-0051-x
149. Ramassone, A., Pagotto, S., Veronese, A. \& Visone, R. Epigenetics and microRNAs in cancer. Int J Mol Sci 19, doi:10.3390/ijms19020459 (2018).

150. Wu, KL., Tsai, YM., Lien, CT., Kuo, PL. \& Hung, AJ. The roles of microRNA in lung cancer. Int J Mol Sci 20, doi:10.3390/ijms20071611 (2019).

151. Reid MA, Dai Z, Locasale JW. The impact of cellular metabolism on chromatin dynamics and epigenetics. Nat Cell Biol. 2017;19:1298-306. https://doi.org/10.1038/ncb3629.

152. Kaelin, WG., Jr. \& McKnight, SL. Influence of metabolism on epigenetics and disease. Cell 153, 56-69, doi:https://doi.org/10.1016/j.cell.2013.03.004 (2013).

153. Shimazu T, et al. Suppression of oxidative stress by beta-hydroxybutyrate, an endogenous histone deacetylase inhibitor. Science. 2013;339:211-4. https:// doi.org/10.1126/science.1227166.

154. Xu W, et al. Oncometabolite 2-hydroxyglutarate is a competitive inhibitor of alpha-ketoglutarate-dependent dioxygenases. Cancer Cell. 2011;19:17-30. https://doi.org/10.1016/j.ccr.2010.12.014.

155. Laskowski Al, Fanslow DA, Smith ED, Kosak ST. Clinical epigenetic therapies disrupt sex chromosome dosage compensation in human female cells. Gend Genome. 2018;2:2-7. https://doi.org/10.1177/2470289718787106.

156. Ward PS, Thompson CB. Metabolic reprogramming: a cancer hallmark even warburg did not anticipate. Cancer Cell. 2012;21:297-308. https://doi.org/10. 1016/j.ccr.2012.02.014

157. Strickland M, Stoll EA. Metabolic reprogramming in glioma. Front Cell Dev Biol. 2017:5:43. https://doi.org/10.3389/fcell.2017.00043.

158. Ray PF, Conaghan J, Winston RM, Handyside AH. Increased number of cells and metabolic activity in male human preimplantation embryos following in vitro fertilization. J Reprod Fertil. 1995;104:165-71. https://doi.org/10.1530/ jrf.0.1040165.

159. Tagirov M, Rutkowska J. Sexual dimorphism in the early embryogenesis in zebra finches. PLoS One. 2014;9:e114625. https://doi.org/10.1371/journal. pone. 0114625

160. Tsunoda $Y$, Tokunaga T, Sugie T. Altered sex ratio of live young after transfer of fast- and slow-developing mouse embryos. Mol Rep Dev. 1985;12:301-4.

161. Valdivia RP, Kunieda T, Azuma S, Toyoda Y. PCR sexing and developmental rate differences in preimplantation mouse embryos fertilized and cultured in vitro. Mol Reprod Dev. 1993;35:121-6. https://doi.org/10.1002/mrd. 1080350204.

162. Alfarawati $S$, et al. The relationship between blastocyst morphology, chromosomal abnormality, and embryo gender. Fertil Steril. 2011;95:520-4. https://doi.org/10.1016/j.fertnstert.2010.04.003

163. Menezo YJ, Chouteau J, Torello J, Girard A, Veiga A. Birth weight and sex ratio after transfer at the blastocyst stage in humans. Fertil Steril. 1999;72: 221-4. https://doi.org/10.1016/s0015-0282(99)00256-3.

164. Geng $X$, et al. Fetal sex influences maternal fasting plasma glucose levels and basal beta-cell function in pregnant women with normal glucose tolerance. Acta Diabetol. 2017;54:1131-8. https://doi.org/10.1007/s00592017-1055-1.

165. Giannubilo SR, Pasculli A, Ballatori C, Biagini A, Ciavattini A. Fetal sex, need for insulin, and perinatal outcomes in gestational diabetes mellitus: an observational cohort study. Clin Ther. 2018;40:587-92. https://doi.org/10. 1016/j.clinthera.2018.02.015.

166. Gutierrez-Adan A, et al. Effect of the in vitro culture system on the kinetics of blastocyst development and sex ratio of bovine embryos. Theriogenology. 2001;55:1117-26.

167. Larson MA, Kimura K, Kubisch HM, Roberts RM. Sexual dimorphism among bovine embryos in their ability to make the transition to expanded blastocyst and in the expression of the signaling molecule IFN-tau. Proc Natl Acad Sci U S A. 2001;98:9677-82. https://doi.org/10.1073/pnas.171305398.

168. Peippo J, Kurkilahti M, Bredbacka P. Developmental kinetics of in vitro produced bovine embryos: the effect of sex, glucose and exposure to timelapse environment. Zygote. 2001;9:105-13.

169. Tiffin GJ, Rieger D, Betteridge KJ, Yadav BR, King WA. Glucose and glutamine metabolism in pre-attachment cattle embryos in relation to sex and stage of development. J Reprod Fertil. 1991;93:125-32. https://doi.org/10.1530/jrf. 0.0930125 .

170. Garcia-Herreros M, Aparicio IM, Rath D, Fair T, Lonergan P. Differential glycolytic and glycogenogenic transduction pathways in male and female bovine embryos produced in vitro. Reprod Fertil Dev. 2012;24:344-52. https://doi.org/10.1071/RD11080.

171. Kimura K, Iwata $H$, Thompson JG. The effect of glucosamine concentration on the development and sex ratio of bovine embryos. Anim Reprod Sci. 2008;103:228-38. https://doi.org/10.1016/j.anireprosci.2006.12.014. 
172. Williams TJ. A technique for sexing mouse embryos by a visual colorimetric assay of the X-linked enzyme, glucose 6-phosphate dehydrogenase. Theriogenology. 1986;25:733-9.

173. Krumsiek J, et al. Gender-specific pathway differences in the human serum metabolome. Metabolomics. 2015;11:1815-33. https://doi.org/10.1007/ s11306-015-0829-0.

174. Christmann V, et al. The enigma to achieve normal postnatal growth in preterm infants--using parenteral or enteral nutrition? Acta Paediatr. 2013; 102:471-9. https://doi.org/10.1111/apa.12188.

175. van den Akker, CH., te Braake, FW., Weisglas-Kuperus, N. \& van Goudoever JB. Observational outcome results following a randomized controlled trial of early amino acid administration in preterm infants. J Pediatr Gastroenterol Nutr 59, 714-719, doi:10.1097/MPG.0000000000000549 (2014).

176. Mittelstrass K, et al. Discovery of sexual dimorphisms in metabolic and genetic biomarkers. PLoS Genet. 2011;7:e1002215. https://doi.org/10.1371/ journal.pgen.1002215.

177. Lamont, LS., McCullough, AJ. \& Kalhan, SC. Gender differences in the regulation of amino acid metabolism. J Appl Physiol (1985) 95, 1259-1265, doi:10.1152/japplphysiol.01028.2002 (2003)

178. Al-Suwailem E, Abdi S, El-Ansary A. Sex differences in the glutamate signaling pathway in juvenile rats. J Neurosci Res. 2018;96:459-66. https:// doi.org/10.1002/jnr.24144.

179. Levin E, McCue MD, Davidowitz G. Sex differences in the utilization of essential and non-essential amino acids in Lepidoptera. J Exp Biol. 2017;220: 2743-7. https://doi.org/10.1242/jeb.154757.

180. Hedrington MS, Davis SN. Sexual dimorphism in glucose and lipid metabolism during fasting, hypoglycemia, and exercise. Front Endocrinol (Lausanne). 2015;6:61. https://doi.org/10.3389/fendo.2015.00061.

181. Palmisano BT, Zhu L, Eckel RH, Stafford JM. Sex differences in lipid and lipoprotein metabolism. Mol Metab. 2018;15:45-55. https://doi.org/10.1016/j. molmet.2018.05.008

182. Kochhar S, et al. Probing gender-specific metabolism differences in humans by nuclear magnetic resonance-based metabonomics. Anal Biochem. 2006; 352:274-81. https://doi.org/10.1016/j.ab.2006.02.033.

183. Frias JP, et al. Decreased susceptibility to fatty acid-induced peripheral tissue insulin resistance in women. Diabetes. 2001;50:1344-50. https://doi.org/10. 2337/diabetes.50.6.1344.

184. Ribas, V. et al. Skeletal muscle action of estrogen receptor alpha is critical for the maintenance of mitochondrial function and metabolic homeostasis in females. Sci Transl Med 8, 334ra354, doi:10.1126/scitranslmed.aad3815 (2016).

185. Ockner RK, Burnett DA, Lysenko N, Manning JA. Sex differences in long chain fatty acid utilization and fatty acid binding protein concentration in rat liver. J Clin Invest. 1979;64:172-81. https://doi.org/10.1172/JCl109437.

186. Hevener A, Reichart D, Janez A, Olefsky J. Female rats do not exhibit free fatty acid-induced insulin resistance. Diabetes. 2002;51:1907-12. https://doi. org/10.2337/diabetes.51.6.1907

187. Fried SK, Kral JG. Sex differences in regional distribution of fat cell size and lipoprotein lipase activity in morbidly obese patients. Int J Obes. 1987;11: $129-40$.

188. Ippolito, JE., Yim, AK., Luo, J., Chinnaiyan, P. \& Rubin, JB. Sexual dimorphism in glioma glycolysis underlies sex differences in survival. JCI Insight 2, doi:10. 1172/jci.insight.92142 (2017).

189. Nguyen GK, Mellnick VM, Yim AK, Salter A, Ippolito JE. Synergy of sex differences in visceral fat measured with $C T$ and tumor metabolism helps predict overall survival in patients with renal cell carcinoma. Radiology. 2018;287:884-92. https://doi.org/10.1148/radiol.2018171504.

190. Anderson NM, Mucka P, Kern JG, Feng H. The emerging role and targetability of the TCA cycle in cancer metabolism. Protein Cell. 2018;9: 216-37. https://doi.org/10.1007/s13238-017-0451-1.

191. Porporato PE, Filigheddu N, Pedro JMB, Kroemer G, Galluzzi L. Mitochondrial metabolism and cancer. Cell Res. 2018;28:265-80. https://doi.org/10.1038/cr. 2017.155 .

192. Munro D, Treberg JR. A radical shift in perspective: mitochondria as regulators of reactive oxygen species. J Exp Biol. 2017;220:1170-80. https:// doi.org/10.1242/jeb.132142

193. Ventura-Clapier R, et al. Mitochondria: a central target for sex differences in pathologies. Clin Sci (Lond). 2017;131:803-22. https://doi.org/10.1042/ CS20160485.

194. Guevara R, et al. Sex-dependent differences in aged rat brain mitochondrial function and oxidative stress. Free Radic Biol Med. 2009:46:169-75. https:// doi.org/10.1016/j.freeradbiomed.2008.09.035.
195. Guevara R, Gianotti M, Roca P, Oliver J. Age and sex-related changes in rat brain mitochondrial function. Cell Physiol Biochem. 2011;27:201-6. https:// doi.org/10.1159/000327945.

196. Gaignard P, et al. Effect of sex differences on brain mitochondrial function and its suppression by ovariectomy and in aged mice. Endocrinology. 2015; 156:2893-904. https://doi.org/10.1210/en.2014-1913.

197. Khalifa, AR. et al. Sex-specific differences in mitochondria biogenesis, morphology, respiratory function, and ROS homeostasis in young mouse heart and brain. Physiol Rep 5, doi:10.14814/phy2.13125 (2017).

198. Escames G, et al. Early gender differences in the redox status of the brain mitochondria with age: effects of melatonin therapy. Horm Mol Biol Clin Investig. 2013;16:91-100. https://doi.org/10.1515/hmbci-2013-0026.

199. Kim HJ, Magrane J, Starkov AA, Manfredi G. The mitochondrial calcium regulator cyclophilin $D$ is an essential component of oestrogen-mediated neuroprotection in amyotrophic lateral sclerosis. Brain. 2012;135:2865-74. https://doi.org/10.1093/brain/aws208.

200. Jaber SM, et al. Sex differences in the mitochondrial bioenergetics of astrocytes but not microglia at a physiologically relevant brain oxygen tension. Neurochem Int. 2018;117:82-90. https://doi.org/10.1016/.j.neuint.2017.09.003.

201. Harish G, et al. Mitochondrial function in human brains is affected by preand post mortem factors. Neuropathol Appl Neurobiol. 2013;39:298-315. https://doi.org/10.1111/j.1365-2990.2012.01285.x.

202. Zawada, I. et al. Gene expression of key regulators of mitochondrial biogenesis is sex dependent in mice with growth hormone receptor deletion in liver. Aging (Albany NY) 7, 195-204, doi:10.18632/aging.100733 (2015).

203. Borras C, et al. Mitochondria from females exhibit higher antioxidant gene expression and lower oxidative damage than males. Free Radic Biol Med. 2003;34:546-52.

204. Ide T, et al. Greater oxidative stress in healthy young men compared with premenopausal women. Arterioscler Thromb Vasc Biol. 2002;22:438-42.

205. Reczek RR, XChandel N. The two faces of reactive oxygen species in cancer. Annual Review of Cancer Biology. 2017;1:79-98. https://doi.org/10.1146/ annurev-cancerbio-041916-065808.

206. Galadari S, Rahman A, Pallichankandy S, Thayyullathil F. Reactive oxygen species and cancer paradox: to promote or to suppress? Free Radic Biol Med. 2017;104:144-64. https://doi.org/10.1016/j.freeradbiomed.2017.01.004.

207. Chiarini F, Evangelisti C, McCubrey JA, Martelli AM. Current treatment strategies for inhibiting mTOR in cancer. Trends Pharmacol Sci. 2015:36:12435. https://doi.org/10.1016/j.tips.2014.11.004.

208. Yang J, et al. Targeting PI3K in cancer: mechanisms and advances in clinical trials. Mol Cancer. 2019;18:26. https://doi.org/10.1186/s12943-019-0954-X.

209. Mossmann D, Park S, Hall MN. mTOR signalling and cellular metabolism are mutual determinants in cancer. Nat Rev Cancer. 2018;18:744-57. https://doi. org/10.1038/s41568-018-0074-8.

210. Rideout EJ, Narsaiya MS, Grewal SS. The sex determination gene transformer regulates male-female differences in drosophila body size. PLoS Genet. 2015;11:e1005683. https://doi.org/10.1371/journal.pgen.1005683.

211. Gurgen, D. et al. Sex-specific mTOR signaling determines sexual dimorphism in myocardial adaptation in normotensive DOCA-salt model. Hypertension 61, 730-736, doi:10.1161/HYPERTENSIONAHA.111.00276 (2013).

212. Lukey MJ, Katt WP, Cerione RA. Targeting amino acid metabolism for cancer therapy. Drug Discov Today. 2017;22:796-804. https://doi.org/10.1016/j. drudis.2016.12.003.

213. Poff $A$, et al. Targeting the Warburg effect for cancer treatment: ketogenic diets for management of glioma. Semin Cancer Biol. 2019;56:135-48. https://doi.org/10.1016/j.semcancer.2017.12.011.

214. Pustylnikov S, Costabile F, Beghi S, Facciabene A. Targeting mitochondria in cancer: current concepts and immunotherapy approaches. Transl Res. 2018; 202:35-51. https://doi.org/10.1016/j.trsl.2018.07.013.

215. Stacpoole, PW. Therapeutic targeting of the pyruvate dehydrogenase complex/pyruvate dehydrogenase kinase (PDC/PDK) Axis in Cancer. J Natl Cancer Inst 109, doi:10.1093/jnci/djx071 (2017).

216. Losman, JA. \& Kaelin, WG., Jr. What a difference a hydroxyl makes: mutant IDH, (R)-2-hydroxyglutarate, and cancer. Genes Dev 27, 836-852, doi:https:// doi.org/10.1101/gad.217406.113 (2013).

217. L, MG., Boulay, K., Topisirovic, I., Huot, ME. \& Mallette, FA. Oncogenic activities of IDH1/2 mutations: from epigenetics to cellular signaling. Trends Cell Biol 27, 738-752, doi:10.1016/j.tcb.2017.06.002 (2017).

218. Dang L, Yen K, Attar EC. IDH mutations in cancer and progress toward development of targeted therapeutics. Ann Oncol. 2016;27:599-608. https:// doi.org/10.1093/annonc/mdw013. 
219. Whitmire, P. et al. Sex-specific impact of patterns of imageable tumor growth on survival of primary glioblastoma patients. bioRxiv, 325464, doi:10 1101/325464 (2018).

220. Chan WM, Siu WY, Lau A, Poon RY. How many mutant p53 molecules are needed to inactivate a tetramer? Mol Cell Biol. 2004;24:3536-51. https://doi. org/10.1128/mcb.24.8.3536-3551.2004.

221. Olivier M, Hollstein M, Hainaut P. TP53 mutations in human cancers: origins, consequences, and clinical use. Cold Spring Harb Perspect Biol. 2010;2: a001008. https://doi.org/10.1101/cshperspect.a001008.

222. Lane DP. Cancer. p53, guardian of the genome. Nature. 1992;358:15-6. https://doi.org/10.1038/358015a0

223. Kastenhuber ER, Lowe SW. Putting p53 in context. Cell. 2017;170:1062-78. https://doi.org/10.1016/j.cell.2017.08.028.

224. Bossi G, et al. Mutant p53 gain of function: reduction of tumor malignancy of human cancer cell lines through abrogation of mutant p53 expression. Oncogene. 2006;25:304-9. https://doi.org/10.1038/sj.onc.1209026.

225. Napoletano F, et al. p53-dependent programmed necrosis controls germ cell homeostasis during spermatogenesis. PLoS Genet. 2017;13:e1007024. https://doi.org/10.1371/journal.pgen.1007024.

226. Hu W. The role of p53 gene family in reproduction. Cold Spring Harb Perspect Biol. 2009;1:a001073. https://doi.org/10.1101/cshperspect. a001073.

227. Chen $X$, et al. Sex difference in neural tube defects in p53-null mice is caused by differences in the complement of $X$ not $Y$ genes. Dev Neurobiol. 2008;68:265-73. https://doi.org/10.1002/dneu.20581.

228. Delbridge, ARD. et al. Loss of p53 causes stochastic aberrant X-chromosome inactivation and female-specific neural tube defects. Cell Rep 27, 442-454 e445, doi:10.1016/j.celrep.2019.03.048 (2019)

229. Yi L, Lu C, Hu W, Sun Y, Levine AJ. Multiple roles of p53-related pathways in somatic cell reprogramming and stem cell differentiation. Cancer Res. 2012; 72:5635-45. https://doi.org/10.1158/0008-5472.CAN-12-1451.

230. Waskar, M. et al. Drosophila melanogaster p53 has developmental stagespecific and sex-specific effects on adult life span indicative of sexual antagonistic pleiotropy. Aging (Albany NY) 1, 903-936, doi:10.18632/aging. 100099 (2009)

231. Lee $J H$, et al. Human glioblastoma arises from subventricular zone cells with low-level driver mutations. Nature. 2018;560:243-7. https://doi.org/10.1038/ s41586-018-0389-3.

232. Liu C, et al. Mosaic analysis with double markers reveals tumor cell of origin in glioma. Cell. 2011;146:209-21. https://doi.org/10.1016/j.cell.2011.06.014

233. Kim JY, Casaccia-Bonnefil P. Interplay of hormones and p53 in modulating gender dimorphism of subventricular zone cell number. J Neurosci Res. 2009;87:3297-305. https://doi.org/10.1002/jnr.21940.

234. Li FP, et al. A cancer family syndrome in twenty-four kindreds. Cancer Res. 1988;48:5358-62.

235. Malkin D, et al. Germ line p53 mutations in a familial syndrome of breast cancer, sarcomas, and other neoplasms. Science. 1990;250:1233-8. https:// doi.org/10.1126/science.1978757.

236. Hwang SJ, Lozano G, Amos Cl, Strong LC. Germline p53 mutations in a cohort with childhood sarcoma: sex differences in cancer risk. Am J Hum Genet. 2003;72:975-83. https://doi.org/10.1086/374567.

237. Chompret $A$, et al. P53 germline mutations in childhood cancers and cancer risk for carrier individuals. Br J Cancer. 2000;82:1932-7. https://doi.org/10. 1054/bjoc.2000.1167.

238. Wu, C C., Shete, S., Amos, Cl. \& Strong, LC. Joint effects of germ-line p53 mutation and sex on cancer risk in Li-Fraumeni syndrome. Cancer Res 66, 8287-8292, doi:10.1158/0008-5472.CAN-05-4247 (2006).

239. Gonzalez KD, et al. Beyond Li Fraumeni syndrome: clinical characteristics of families with p53 germline mutations. J Clin Oncol. 2009;27:1250-6. https:// doi.org/10.1200/JCO.2008.16.6959.

240. Olivier M, et al. Li-Fraumeni and related syndromes: correlation between tumor type, family structure, and TP53 genotype. Cancer Res. 2003;63: $6643-50$.

241. Ribeiro RC, Pinto EM, Zambetti GP, Rodriguez-Galindo C. The International Pediatric Adrenocortical Tumor Registry initiative: contributions to clinical, biological, and treatment advances in pediatric adrenocortical tumors. Mo Cell Endocrinol. 2012;351:37-43. https://doi.org/10.1016/j.mce.2011.10.015.

242. Kebebew E, Reiff E, Duh QY, Clark OH, McMillan A. Extent of disease at presentation and outcome for adrenocortical carcinoma: have we made progress? World J Surg. 2006;30:872-8. https://doi.org/10.1007/s00268005-0329-x.
243. Zhang, Y. et al. The p53 pathway in glioblastoma. Cancers (Basel) 10, doi:10. 3390/cancers10090297 (2018).

244. Bond GL, Hu W, Levine AJ. MDM2 is a central node in the p53 pathway: 12 years and counting. Curr Cancer Drug Targets. 2005;5:3-8. https://doi.org/10. 2174/1568009053332627.

245. Haupt Y, Maya R, Kazaz A, Oren M. Mdm2 promotes the rapid degradation of p53. Nature. 1997;387:296-9. https://doi.org/10.1038/387296a0.

246. Gu B, Zhu WG. Surf the post-translational modification network of p53 regulation. Int J Biol Sci. 2012;8:672-84. https://doi.org/10.7150/ijbs. 4283.

247. Oliner, JD., Saiki, AY. \& Caenepeel, S. The role of MDM2 amplification and overexpression in tumorigenesis. Cold Spring Harb Perspect Med 6, doi:10. 1101/cshperspect.a026336 (2016)

248. Bond GL, et al. A single nucleotide polymorphism in the MDM2 promoter attenuates the p53 tumor suppressor pathway and accelerates tumor formation in humans. Cell. 2004;119:591-602. https://doi.org/10.1016/j.cell. 2004.11.022.

249. Bond GL, et al. MDM2 SNP309 accelerates tumor formation in a genderspecific and hormone-dependent manner. Cancer Res. 2006;66:5104-10. https://doi.org/10.1158/0008-5472.CAN-06-0180.

250. Haupt $S$, et al. Identification of cancer sex-disparity in the functional integrity of p53 and its X chromosome network. Nat Commun. 2019;10: 5385. https://doi.org/10.1038/s41467-019-13266-3.

251. Bykov VJN, Eriksson SE, Bianchi J, Wiman KG. Targeting mutant p53 for efficient cancer therapy. Nat Rev Cancer. 2018;18:89-102. https://doi.org/10. 1038/nrc.2017.109.

252. Golubovskaya VM, Cance WG. Targeting the p53 pathway. Surg Oncol Clin N Am. 2013;22:747-64. https://doi.org/10.1016/j.soc.2013.06.003.

253. Hernandez-Segura A, Nehme J, Demaria M. Hallmarks of cellular senescence. Trends Cell Biol. 2018;28:436-53. https://doi.org/10.1016/j.tcb.2018.02.001.

254. Rao SG, Jackson JG. SASP: tumor suppressor or promoter? Yes! Trends Cancer. 2016;2:676-87. https://doi.org/10.1016/j.trecan.2016.10.001.

255. Coppe JP, Desprez PY, Krtolica A, Campisi J. The senescence-associated secretory phenotype: the dark side of tumor suppression. Annu Rev Pathol. 2010;5:99-118. https://doi.org/10.1146/annurev-pathol-121808-102144.

256. Acosta JC, et al. A complex secretory program orchestrated by the inflammasome controls paracrine senescence. Nat Cell Biol. 2013;15:978-90. https://doi.org/10.1038/ncb2784.

257. Kansara M, et al. Immune response to RB1-regulated senescence limits radiation-induced osteosarcoma formation. J Clin Invest. 2013;123:5351-60. https://doi.org/10.1172/JCl70559.

258. Krzymowski T, Stefanczyk-Krzymowska S. Advances in understanding the physiological mechanism of maternal immune tolerance to the embryo. Reprod Biol. 2012;12:265-70. https://doi.org/10.1016/j.repbio.2012.10.004.

259. Ruhland MK, et al. Stromal senescence establishes an immunosuppressive microenvironment that drives tumorigenesis. Nat Commun. 2016;7:11762. https://doi.org/10.1038/ncomms11762.

260. Sagiv A, Krizhanovsky V. Immunosurveillance of senescent cells: the bright side of the senescence program. Biogerontology. 2013;14:617-28. https:// doi.org/10.1007/s10522-013-9473-0.

261. Krizhanovsky $V$, et al. Senescence of activated stellate cells limits liver fibrosis. Cell. 2008;134:657-67. https://doi.org/10.1016/j.cell.2008.06.049.

262. Coppe JP, et al. Senescence-associated secretory phenotypes reveal cellnonautonomous functions of oncogenic RAS and the p53 tumor suppressor. PLoS Biol. 2008;6:2853-68. https://doi.org/10.1371/journal.pbio. 0060301.

263. Kang TW, et al. Senescence surveillance of pre-malignant hepatocytes limits liver cancer development. Nature. 2011;479:547-51. https://doi.org/10.1038/ nature10599.

264. Toso A, et al. Enhancing chemotherapy efficacy in Pten-deficient prostate tumors by activating the senescence-associated antitumor immunity. Cell Rep. 2014:9:75-89. https://doi.org/10.1016/j.celrep.2014.08.044.

265. Austad SN, Fischer KE. Sex Differences in Lifespan. Cell Metab. 2016;23:102233. https://doi.org/10.1016/j.cmet.2016.05.019.

266. Marais $G A B$, et al. Sex gap in aging and longevity: can sex chromosomes play a role? Biol Sex Differ. 2018;9:33. https://doi.org/10.1186/s13293-0180181-y.

267. Ostan R, et al. Gender, aging and longevity in humans: an update of an intriguing/neglected scenario paving the way to a gender-specific medicine. Clin Sci (Lond). 2016:130:1711-25. https://doi.org/10.1042/ CS20160004. 
268. Baker DJ, et al. Clearance of p16lnk4a-positive senescent cells delays ageingassociated disorders. Nature. 2011;479:232-6. https://doi.org/10.1038/ nature 10600.

269. Baker DJ, et al. Naturally occurring p16(Ink4a)-positive cells shorten healthy lifespan. Nature. 2016;530:184-9. https://doi.org/10.1038/nature16932.

270. Bussian TJ, et al. Clearance of senescent glial cells prevents tau-dependent pathology and cognitive decline. Nature. 2018;562:578-82. https://doi.org/ 10.1038/s41586-018-0543-y.

271. Musi N, et al. Tau protein aggregation is associated with cellular senescence in the brain. Aging Cell. 2018;17:e12840. https://doi.org/10.1111/acel.12840.

272. Childs BG, et al. Senescent intimal foam cells are deleterious at all stages of atherosclerosis. Science. 2016;354:472-7. https://doi.org/10.1126/science. aaf6659.

273. Jeon $\mathrm{OH}$, David N, Campisi J, Elisseeff $\mathrm{JH}$. Senescent cells and osteoarthritis: a painful connection. J Clin Invest. 2018;128:1229-37. https://doi.org/10. $1172 / J C 195147$.

274. Storer $M$, et al. Senescence is a developmental mechanism that contributes to embryonic growth and patterning. Cell. 2013;155:1119-30. https://doi. org/10.1016/j.cell.2013.10.041.

275. Howlader, N. et al. (National Cancer Institute, 2013).

276. Bitto A, et al. Stress-induced senescence in human and rodent astrocytes. Exp Cell Res. 2010;316:2961-8. https://doi.org/10.1016/j.yexcr.2010.06.021.

277. Chinta SJ, et al. Cellular senescence and the aging brain. Exp Gerontol. 2015; 68:3-7. https://doi.org/10.1016/j.exger.2014.09.018.

278. Kritsilis, M. et al. Ageing, cellular senescence and neurodegenerative disease. Int J Mol Sci 19, doi:10.3390/ijms19102937 (2018).

279. Kujuro Y, Suzuki N, Kondo T. Esophageal cancer-related gene 4 is a secreted inducer of cell senescence expressed by aged CNS precursor cells. Proc Natl Acad Sci U S A. 2010;107:8259-64. https://doi.org/10.1073/pnas.0911446107.

280. Fischer KE, Riddle NC. Sex differences in aging: genomic instability. J Gerontol A Biol Sci Med Sci. 2018;73:166-74. https://doi.org/10.1093/gerona/ glx105.

281. Gallagher CJ, Balliet RM, Sun D, Chen G, Lazarus P. Sex differences in UDPglucuronosyltransferase 2B17 expression and activity. Drug Metab Dispos. 2010;38:2204-9. https://doi.org/10.1124/dmd.110.035345.

282. Scandlyn MJ, Stuart EC, Rosengren RJ. Sex-specific differences in CYP450 isoforms in humans. Expert Opin Drug Metab Toxicol. 2008;4:413-24.

283. Kollarovic, G. et al. To senesce or not to senesce: how primary human fibroblasts decide their cell fate after DNA damage. Aging (Albany NY) 8, 158-177, doi:10.18632/aging.100883 (2016).

284. Malorni W, et al. Redox state and gender differences in vascular smooth muscle cells. FEBS Lett. 2008;582:635-42. https://doi.org/10.1016/j.febslet. 2008.01.034

285. Krauthacker B. Levels of organochlorine pesticides and polychlorinated biphenyls (PCBs) in human milk and serum collected from lactating mothers in the northern Adriatic area of Yugoslavia. Bull Environ Contam Toxicol. 1991;46:797-802. https://doi.org/10.1007/bf01689721.

286. Levine AJ. p53, the cellular gatekeeper for growth and division. Cell. 1997; 88:323-31. https://doi.org/10.1016/s0092-8674(00)81871-1.

287. Yousefzadeh, M. J. et al. Tissue specificity of senescent cell accumulation during physiologic and accelerated aging of mice. Aging Cell, e13094, doi: 10.1111/acel.13094 (2020).

288. Demaria $M$, et al. Cellular senescence promotes adverse effects of chemotherapy and cancer relapse. Cancer Discov. 2017;7:165-76. https:// doi.org/10.1158/2159-8290.CD-16-0241.

289. Velarde MC, Demaria M, Campisi J. Senescent cells and their secretory phenotype as targets for cancer therapy. Interdiscip Top Gerontol. 2013;38: 17-27. https://doi.org/10.1159/000343572.

290. Short S, Fielder E, Miwa S, von Zglinicki T. Senolytics and senostatics as adjuvant tumour therapy. EBioMedicine. 2019;41:683-92. https://doi.org/10 1016/j.ebiom.2019.01.056.

291. Sherr CI, Beach D, Shapiro Gl. Targeting CDK4 and CDK6: from discovery to therapy. Cancer Discov. 2016;6:353-67. https://doi.org/10.1158/2159-8290.CD-15-0894.

292. Paez-Ribes, M., Gonzalez-Gualda, E., Doherty, GJ. \& Munoz-Espin, D. Targeting senescent cells in translational medicine. EMBO Mol Med 11, e10234, doi:10.15252/emmm.201810234 (2019).

293. Vinay, DS. et al. Immune evasion in cancer: mechanistic basis and therapeutic strategies. Semin Cancer Biol 35 Suppl, S185-S198, doi:10.1016/j. semcancer.2015.03.004 (2015).

294. Hanahan D, Weinberg RA. Hallmarks of cancer: the next generation. Cell. 2011;144:646-74. https://doi.org/10.1016/j.cell.2011.02.013.
295. Jacobs JF, Nierkens S, Figdor CG, de Vries IJ, Adema GJ. Regulatory T cells in melanoma: the final hurdle towards effective immunotherapy? Lancet Oncol. 2012;13:e32-42. https://doi.org/10.1016/S1470-2045(11)70155-3.

296. Restifo NP, et al. Identification of human cancers deficient in antigen processing. J Exp Med. 1993;177:265-72. https://doi.org/10.1084/jem.177. 2.265 .

297. Sotomayor EM, et al. Role of tumor-derived cytokines on the immune system of mice bearing a mammary adenocarcinoma. II. Down-regulation of macrophage-mediated cytotoxicity by tumor-derived granulocytemacrophage colony-stimulating factor. J Immunol. 1991;147:2816-23.

298. Foell J, Hewes B, Mittler RS. T cell costimulatory and inhibitory receptors as therapeutic targets for inducing anti-tumor immunity. Curr Cancer Drug Targets. 2007;7:55-70.

299. Topalian SL, Drake CG, Pardoll DM. Targeting the PD-1/B7-H1(PD-L1) pathway to activate anti-tumor immunity. Curr Opin Immunol. 2012;24:20712. https://doi.org/10.1016/j.coi.2011.12.009.

300. Cook MB, et al. Sex disparities in cancer incidence by period and age. Cancer epidemiology, biomarkers \& prevention : a publication of the American Association for Cancer Research, cosponsored by the American Society of Preventive Oncology. 2009;18:1174-82. https://doi.org/10.1158/ 1055-9965.EPI-08-1118.

301. Weinstein Y, Ran S, Segal S. Sex-associated differences in the regulation of immune responses controlled by the MHC of the mouse. J Immunol. 1984; 132:656-61.

302. Wang $L$, et al. Programmed death 1 ligand signaling regulates the generation of adaptive Foxp3 + CD4+ regulatory T cells. Proc Natl Acad Sci U S A. 2008;105:9331-6. https://doi.org/10.1073/pnas.0710441105.

303. Lin PY, et al. B7-H1-dependent sex-related differences in tumor immunity and immunotherapy responses. J Immunol. 2010;185:2747-53. https://doi. org/10.4049/jimmunol.1000496.

304. Scotland RS, Stables MJ, Madalli S, Watson P, Gilroy DW. Sex differences in resident immune cell phenotype underlie more efficient acute inflammatory responses in female mice. Blood. 2011;118:5918-27. https://doi.org/10.1182/ blood-2011-03-340281.

305. Laffont S, Blanquart E, Guery JC. Sex differences in asthma: a key role of androgen-signaling in group 2 innate lymphoid cells. Front Immunol. 2017; 8:1069. https://doi.org/10.3389/fimmu.2017.01069.

306. Bosch FX, Ribes J, Diaz M, Cleries R. Primary liver cancer: worldwide incidence and trends. Gastroenterology. 2004;127:S5-S16. https://doi.org/10. 1053/j.gastro.2004.09.011.

307. Kumari N, Dwarakanath BS, Das A, Bhatt AN. Role of interleukin-6 in cancer progression and therapeutic resistance. Tumour Biol. 2016;37:11553-72. https://doi.org/10.1007/s13277-016-5098-7.

308. Caetano MS, et al. Sex specific function of epithelial STAT3 signaling in pathogenesis of K-ras mutant lung cancer. Nat Commun. 2018;9:4589. https://doi.org/10.1038/s41467-018-07042-y.

309. Dogan S, et al. Molecular epidemiology of EGFR and KRAS mutations in 3,026 lung adenocarcinomas: higher susceptibility of women to smokingrelated KRAS-mutant cancers. Clin Cancer Res. 2012;18:6169-77. https://doi. org/10.1158/1078-0432.CCR-11-3265.

310. Araujo, JM. et al. Repeated observation of immune gene sets enrichment in women with non-small cell lung cancer. Oncotarget 7, 20282-20292, doi:10. 18632/oncotarget.7943 (2016).

311. Hewagama A, Patel D, Yarlagadda S, Strickland FM, Richardson BC. Stronger inflammatory/cytotoxic T-cell response in women identified by microarray analysis. Genes Immun. 2009;10:509-16. https://doi.org/10.1038/gene.2009.12.

312. Fish EN. The X-files in immunity: sex-based differences predispose immune responses. Nat Rev Immunol. 2008;8:737-44. https://doi.org/10.1038/nri2394.

313. Zhang MA, et al. Peroxisome proliferator-activated receptor (PPAR)alpha and -gamma regulate IFNgamma and IL-17A production by human T cells in a sex-specific way. Proc Natl Acad Sci U S A. 2012;109:9505-10. https://doi. org/10.1073/pnas.1118458109.

314. Asadzadeh Z, et al. The paradox of Th17 cell functions in tumor immunity. Cell Immunol. 2017;322:15-25. https://doi.org/10.1016/j.cellimm.2017.10.015.

315. Antohe $M$, et al. Tumor infiltrating lymphocytes: the regulator of melanoma evolution. Oncol Lett. 2019;17:4155-61. https://doi.org/10.3892/ol.2019.9940.

316. Kovats $S$. Estrogen receptors regulate innate immune cells and signaling pathways. Cell Immunol. 2015;294:63-9. https:/doi.org/10.1016/j.cellimm.2015.01.018.

317. Laffont S, Seillet C, Guery JC. Estrogen receptor-dependent regulation of dendritic cell development and function. Front Immunol. 2017;8:108. https://doi.org/10.3389/fimmu.2017.00108. 
318. Abdullah $M$, et al. Gender effect on in vitro lymphocyte subset levels of healthy individuals. Cell Immunol. 2012;272:214-9. https://doi.org/10.1016/j. cellimm.2011.10.009.

319. Capone I, Marchetti P, Ascierto PA, Malorni W, Gabriele L. Sexual dimorphism of immune responses: a new perspective in cancer immunotherapy. Front Immunol. 2018;9:552. https://doi.org/10.3389/fimmu. 2018.00552

320. Dyck L, Mills KHG. Immune checkpoints and their inhibition in cancer and infectious diseases. Eur J Immunol. 2017;47:765-79. https://doi.org/10.1002/ eji.201646875.

321. Pinto JA, et al. Gender and outcomes in non-small cell lung cancer: an old prognostic variable comes back for targeted therapy and immunotherapy? ESMO Open. 2018;3:e000344. https://doi.org/10.1136/esmoopen-2018000344

322. Wang S, Zhang J, He Z, Wu K, Liu XS. The predictive power of tumor mutational burden in lung cancer immunotherapy response is influenced by patients' sex. Int J Cancer. 2019;145:2840-9. https://doi.org/10.1002/ijc. 32327.

323. Duma $N$, et al. Sex Differences in tolerability to anti-programmed cell death protein 1 therapy in patients with metastatic melanoma and non-small cell lung cancer: are we all equal? Oncologist. 2019;24:e1148-55. https://doi.org/ 10.1634/theoncologist.2019-0094.

324. Polanczyk MJ, Hopke C, Vandenbark AA, Offner H. Treg suppressive activity involves estrogen-dependent expression of programmed death-1 (PD-1). Int Immunol. 2007;19:337-43. https://doi.org/10.1093/intimm/dxl151.

325. Grenda A, Krawczyk P. New dancing couple: PD-L1 and microRNA. Scand Immunol. 2017:86:130-4. https://doi.org/10.1111/sji.12577.

326. Smolle MA, Calin HN, Pichler M, Calin GA. Noncoding RNAs and immune checkpoints-clinical implications as cancer therapeutics. FEBS J. 2017;284: 1952-66. https://doi.org/10.1111/febs.14030.

327. Pinheiro I. Dejager, L. \& Libert, CX-chromosome-located microRNAs in immunity: might they explain male/female differences? The $\mathrm{X}$ chromosomegenomic context may affect $X$-located miRNAs and downstream signaling, thereby contributing to the enhanced immune response of females. Bioessays. 2011;33:791-802. https://doi.org/10.1002/bies.201100047.

328. Hanahan D, Weinberg RA. The hallmarks of cancer. Cell. 2000;100:57-70. https://doi.org/10.1016/s0092-8674(00)81683-9.

329. Demir R, Yaba A, Huppertz B. Vasculogenesis and angiogenesis in the endometrium during menstrual cycle and implantation. Acta Histochem. 2010;112:203-14. https://doi.org/10.1016/j.acthis.2009.04.004.

330. Brogi $E$, et al. Hypoxia-induced paracrine regulation of vascular endothelial growth factor receptor expression. The Journal of clinical investigation 1996;97:469-76. https://doi.org/10.1172/JCl118437.

331. Fernando NT, et al. Tumor escape from endogenous, extracellular matrixassociated angiogenesis inhibitors by up-regulation of multiple proangiogenic factors. Clinical cancer research : an official journal of the American Association for Cancer Research. 2008;14:1529-39. https://doi.org/ 10.1158/1078-0432.CCR-07-4126.

332. Olsson AK, Dimberg A, Kreuger J, Claesson-Welsh L. VEGF receptor signalling - in control of vascular function. Nat Rev Mol Cell Biol. 2006;7: 359-71. https://doi.org/10.1038/nrm1911.

333. Biel NM, Siemann DW. Targeting the Angiopoietin-2/Tie-2 axis in conjunction with VEGF signal interference. Cancer Letters. 2016;380:525-33. https://doi.org/10.1016/j.canlet.2014.09.035.

334. Claesson-Welsh L, Welsh M. VEGFA and tumour angiogenesis. Journal of internal medicine. 2013;273:114-27. https://doi.org/10.1111/joim.12019.

335. Ferrara N. Vascular endothelial growth factor: basic science and clinical progress. Endocrine reviews. 2004;25:581-611. https://doi.org/10.1210/er 2003-0027.

336. Imoukhuede PI, Popel AS. Quantification and cell-to-cell variation of vascular endothelial growth factor receptors. Exp Cell Res. 2011;317:955-65. https:// doi.org/10.1016/j.yexcr.2010.12.014

337. Avraamides, CJ., Garmy-Susini, B. \& Varner, JA. in Nature Reviews Cancer (2008).

338. Kuczynski EA, Patten SG, Coomber BL. VEGFR2 expression and TGF-beta signaling in initial and recurrent high-grade human glioma. Oncology. 2011 81:126-34. https://doi.org/10.1159/000332849.

339. Garmy-Susini B, Varner JA. Circulating endothelial progenitor cells. British Journal of Cancer. 2005;93:855-8. https://doi.org/10.1038/sj.bjc.6602808.

340. Kroll J, Waltenberger J. VEGF-A induces expression of eNOS and iNOS in endothelial cells via VEGF receptor-2 (KDR). Biochem Biophys Res Commun. 1998;252:743-6. https://doi.org/10.1006/bbrc.1998.9719.
341. Stamenkovic I. Extracellular matrix remodelling: the role of matrix metalloproteinases. J Pathol. 2003;200:448-64. https://doi.org/10.1002/ path.1400.

342. Hanahan D, Folkman J. Patterns and emerging mechanisms of the angiogenic switch during tumorigenesis. Cell. 1996;86:353-64. https://doi. org/10.1016/s0092-8674(00)80108-7.

343. Folkman J, D'Amore PA. Blood vessel formation: what is its molecular basis? Cell. 1996;87:1153-5. https://doi.org/10.1016/s0092-8674(00)81810-3.

344. Du L, et al. Starving neurons show sex difference in autophagy. J Biol Chem 2009;284:2383-96. https://doi.org/10.1074/jbc.M804396200.

345. De Francesco EM, et al. HIF-1a/GPER signaling mediates the expression of VEGF induced by hypoxia in breast cancer associated fibroblasts (CAFs). Breast Cancer Research. 2013;15:R64. https://doi.org/10.1186/bcr3458.

346. Lin EY, Pollard JW. in. Cancer Research. 2007;67:5064-6.

347. Schoppmann SF, et al. Tumor-associated macrophages express lymphatic endothelial growth factors and are related to peritumoral lymphangiogenesis. Am J Pathol. 2002;161:947-56. https://doi.org/10.1016/ S0002-9440(10)64255-1.

348. Morikawa S, et al. Abnormalities in pericytes on blood vessels and endothelial sprouts in tumors. Am J Pathol. 2002;160:985-1000. https://doi. org/10.1016/S0002-9440(10)64920-6.

349. Carmeliet $P$, Jain RK. Angiogenesis in cancer and other diseases. Nature. 2000;407:249-57. https://doi.org/10.1038/35025220.

350. Dubois $C$, et al. Lymph/angiogenesis contribute to sex differences in lung cancer through ERalpha signalling. Endocr Relat Cancer. 2018. https://doi. org/10.1530/ERC-18-0328.

351. Addis R, et al. Human umbilical endothelial cells (HUVECs) have a sex: characterisation of the phenotype of male and female cells. Biol Sex Differ. 2014;5:18. https://doi.org/10.1186/s13293-014-0018-2.

352. Huxley VH, et al. Sex differences influencing micro- and macrovascular endothelial phenotype in vitro. J Physiol. 2018;596:3929-49. https://doi.org/ 10.1113/JP276048.

353. Imoukhuede PI, Popel AS. Expression of VEGF receptors on endothelial cells in mouse skeletal muscle. PLoS One. 2012;7:e44791. https://doi.org/10.1371/ journal.pone.0044791.

354. Cattaneo MG, et al. Sex-specific eNOS activity and function in human endothelial cells. Scientific Reports. 2017;7:9612. https://doi.org/10.1038/ s41598-017-10139-x.

355. Schaaf MB, Houbaert D, Mece O, Agostinis P. Autophagy in endothelial cells and tumor angiogenesis. Cell Death Differ. 2019;26:665-79. https://doi.org/ 10.1038/s41418-019-0287-8.

356. Boese, AC., Kim, SC., Yin, KJ., Lee, JP. \& Hamblin, MH. in American Journal of Physiology - Heart and Circulatory Physiology Vol. 313 H524-H545 (American Physiological Society, 2017).

357. Herrmann $J \mathbf{L}$, et al. in. Journal of Cardiovascular Translational Research. 2010; 3:103-13.

358. Kim KH, Young BD, Bender JR. Endothelial estrogen receptor isoforms and cardiovascular disease. Mol Cell Endocrinol. 2014;389:65-70. https://doi.org/ 10.1016/j.mce.2014.02.001.

359. Wyckoff MH, et al. Plasma membrane estrogen receptors are coupled to endothelial nitric-oxide synthase through Galpha(i). J Biol Chem. 2001;276: 27071-6. https://doi.org/10.1074/jbc.M100312200.

360. Likhite, N. et al. Loss of estrogen-related receptor alpha facilitates angiogenesis in endothelial cells. Mol Cell Biol 39, doi:10.1128/MCB.00411-18 (2019).

361. Lu Q, et al. ER Alpha rapid signaling is required for estrogen induced proliferation and migration of vascular endothelial cells. PLoS One. 2016;11: e0152807. https://doi.org/10.1371/journal.pone.0152807.

362. Sieveking, D. P. et al. A sex-specific role for androgens in angiogenesis. J Exp Med 207, 345-352, doi:10.1084/jem.20091924 (2010).

363. Fadini, GP. et al. Gender differences in endothelial progenitor cells and cardiovascular risk profile: the role of female estrogens. Arteriosclerosis, thrombosis, and vascular biology 28, 997-1004, doi:10.1161/ATVBAHA.107. 159558 (2008)

364. Topel, ML. et al. Sex differences in circulating progenitor cells. J Am Heart Assoc 6, doi:10.1161/JAHA.117.006245 (2017).

365. Ruifrok WP, et al. Estradiol-induced, endothelial progenitor cell-mediated neovascularization in male mice with hind-limb ischemia. Vasc Med. 2009; 14:29-36. https://doi.org/10.1177/1358863X08096666.

366. Navarro FC, Herrnreiter C, Nowak L, Watkins SK. Estrogen regulation of T-cell function and its impact on the tumor microenvironment. Gender and the Genome. 2018;2:81-91. https://doi.org/10.1177/2470289718801379. 
367. Boudreau N, Myers C. Breast cancer-induced angiogenesis: multiple mechanisms and the role of the microenvironment. Breast Cancer Res 2003;5:140-6. https://doi.org/10.1186/bcr589.

368. Rudnicki $M$, et al. Female mice have higher angiogenesis in perigonadal adipose tissue than males in Response to High-Fat Diet. Front Physiol. 2018; 9:1452. https://doi.org/10.3389/fphys.2018.01452.

369. Keselman A, Fang X, White PB, Heller NM. Estrogen signaling contributes to sex differences in macrophage polarization during asthma. J Immunol. 2017; 199:1573-83. https://doi.org/10.4049/jimmunol.1601975.

370. Losordo DW, Isner JM. Estrogen and angiogenesis: a review. Arterioscler Thromb Vasc Biol. 2001;21:6-12. https://doi.org/10.1161/01.atv.21.1.6.

371. Linderholm B, Tavelin B, Grankvist K, Henriksson R. Does vascular endothelial growth factor (VEGF) predict local relapse and survival in radiotherapytreated node-negative breast cancer? Br J Cancer. 1999;81:727-32. https:// doi.org/10.1038/sj.bjc.6690755.

372. Marquez-Garban DC, et al. Progesterone and estrogen receptor expression and activity in human non-small cell lung cancer. Steroids. 2011;76:910-20. https://doi.org/10.1016/j.steroids.2011.04.015.

373. Evanson JR, et al. Gender and age differences in growth factor concentrations from platelet-rich plasma in adults. Military Medicine. 2014; 179:799-805. https://doi.org/10.7205/milmed-d-13-00336.

374. Xiong $\mathrm{G}$, et al. Men and women differ in the biochemical composition of platelet-rich plasma. Am J Sports Med. 2018;46:409-19. https://doi.org/10. 1177/0363546517740845.

375. Ramsey JM, et al. Molecular sex differences in human serum. PLoS One. 2012;7:e51504. https://doi.org/10.1371/journal.pone.0051504.

376. Institute, NC. Angiogenesis Inhibitors, <https://www.cancer.gov/aboutcancer/treatment/types/immunotherapy/angiogenesis-inhibitors-fact-sheet> (2018).

377. Ribatti D, Annese T, Ruggieri S, Tamma R, Crivellato E. Limitations of antiangiogenic treatment of tumors. Transl Oncol. 2019;12:981-6. https://doi. org/10.1016/j.tranon.2019.04.022.

378. Jain RK. Antiangiogenesis strategies revisited: from starving tumors to alleviating hypoxia. Cancer Cell. 2014;26:605-22. https://doi.org/10.1016/j. ccell.2014.10.006.

379. Kim HI, Lim H, Moon A. Sex differences in cancer: epidemiology, genetics and therapy. Biomol Ther (Seoul). 2018;26:335-42. https://doi.org/10.4062/ biomolther.2018.103

380. Brahmer JR, et al. Sex differences in outcome with bevacizumab therapy: analysis of patients with advanced-stage non-small cell lung cancer treated with or without bevacizumab in combination with paclitaxel and carboplatin in the eastern cooperative oncology group trial 459. Journal of Thoracic Oncology. 2011;6:103-8. https://doi.org/10.1097/JTO. 0b013e3181fa8efd.

381. Lu JF, et al. Clinical pharmacokinetics of bevacizumab in patients with solid tumors. Cancer Chemother Pharmacol. 2008;62:779-86. https://doi.org/10. 1007/s00280-007-0664-8

382. Ward EM, et al. Annual report to the nation on the status of cancer, featuring cancer in men and women age 20-49 years. J Natl Cancer Inst. 2019;111:1279-97. https://doi.org/10.1093/jnci/djz106.

383. Imoukhuede PI, Dokun AO, Annex BH, Popel AS. Endothelial cell-by-cell profiling reveals the temporal dynamics of VEGFR1 and VEGFR2 membrane localization after murine hindlimb ischemia. Am J Physiol Heart Circ Physiol. 2013;304:H1085-93. https://doi.org/10.1152/ajpheart.00514.2012.

384. Imoukhuede PI, Popel AS. Quantitative fluorescent profiling of VEGFRs reveals tumor cell and endothelial cell heterogeneity in breast cancer xenografts. Cancer Med. 2014;3:225-44. https://doi.org/10.1002/cam4.188.

385. Chen S, Le T, Harley BAC, Imoukhuede PI. Characterizing glioblastoma heterogeneity via single-cell receptor quantification. Front. Bioeng. Biotechnol. 2018;6:92. https://doi.org/10.3389/fbioe.2018.00092.

386. Chen S, Guo X, Imarenezor O, Imoukhuede PI. Quantification of VEGFRs, NRP1, and PDGFRs on endothelial cells and fibroblasts reveals serum, intrafamily ligand, and cross-family ligand regulation. Cellular and Molecular Bioengineering. 2015;8:383-403. https://doi.org/10.1007/s12195-015-0411-x.

387. Weddell JC, Imoukhuede PI. Quantitative characterization of cellular membrane-receptor heterogeneity through statistical and computational modeling. PLoS One. 2014;9:e97271. https://doi.org/10.1371/journal.pone. 0097271.

388. Finley SD, Engel-Stefanini MO, Imoukhuede PI, Popel AS. Pharmacokinetics and pharmacodynamics of VEGF-neutralizing antibodies. BMC Syst Biol. 2011;5:193. https://doi.org/10.1186/1752-0509-5-193.
389. Mac Gabhann F, Popel AS. Systems biology of vascular endothelial growth factors. Microcirculation. 2008;15:715-38. https://doi.org/10.1080/ 10739680802095964

390. Finley SD, Chu L-H, Popel AS. Computational systems biology approaches to anti-angiogenic cancer therapeutics. Drug discovery today. 2015;20:18797. https://doi.org/10.1016/j.drudis.2014.09.026

391. Mac Gabhann F, Qutub AA, Annex BH, Popel AS. Systems biology of proangiogenic therapies targeting the VEGF system. Wiley Interdiscip Rev Syst Biol Med. 2010;2:694-707. https://doi.org/10.1002/wsbm.92.

392. Qutub, AA., Mac Gabhann, F., Karagiannis, ED., Vempati, P. \& Popel, AS. Multiscale models of angiogenesis. IEEE Eng Med Biol Mag 28, 14-31, doi:10. 1109/MEMB.2009.931791 (2009).

393. Vempati P, Popel AS, Mac Gabhann F. Formation of VEGF isoform-specific spatial distributions governing angiogenesis: computational analysis. BMC Syst Biol. 2011;5:59. https://doi.org/10.1186/1752-0509-5-59.

394. Vempati P, Mac Gabhann F, Popel AS. Quantifying the proteolytic release of extracellular matrix-sequestered VEGF with a computational model. PLoS One. 2010;5:e11860. https://doi.org/10.1371/journal.pone.0011860.

395. Mac Gabhann, F., Ji, J. W. \& Popel, AS. VEGF gradients, receptor activation, and sprout guidance in resting and exercising skeletal muscle. J Appl Physiol (1985) 102, 722-734, doi:10.1152/japplphysiol.00800.2006 (2007).

396. Liu, G., Qutub, A. A., Vempati, P., Mac Gabhann, F. \& Popel, AS. Modulebased multiscale simulation of angiogenesis in skeletal muscle. Theor Biol Med Model 8, 6, doi:10.1186/1742-4682-8-6 (2011).

397. Qutub AA, Popel AS. Elongation, proliferation \& migration differentiate endothelial cell phenotypes and determine capillary sprouting. BMC Syst Biol. 2009;3:13. https://doi.org/10.1186/1752-0509-3-13.

398. Ji JW, Mac Gabhann F, Popel AS. Skeletal muscle VEGF gradients in peripheral arterial disease: simulations of rest and exercise. Am J Physiol Heart Circ Physiol. 2007;293:H3740-9. https://doi.org/10.1152/ajpheart.00009.2007.

399. Weickhardt AJ, et al. Vascular endothelial growth factor D expression is a potential biomarker of bevacizumab benefit in colorectal cancer. $\mathrm{Br} J$ Cancer. 2015;113:37-45. https://doi.org/10.1038/bjc.2015.209.

400. Gail M, Simon R. Testing for qualitative interactions between treatment effects and patient subsets. Biometrics. 1985;41:361-72.

401. Piantadosi S, Gail MH. A comparison of the power of two tests for qualitative interactions. Stat Med. 1993;12:1239-48.

402. Lachenbruch PA. A note on sample size computation for testing interactions. Stat Med. 1988;7:467-9.

403. Demidenko E. Sample size and optimal design for logistic regression with binary interaction. Stat Med. 2008;27:36-46. https://doi.org/10.1002/sim.2980.

404. Schmoor C, Sauerbrei W, Schumacher M. Sample size considerations for the evaluation of prognostic factors in survival analysis. Stat Med. 2000;19:441-52.

\section{Publisher's Note}

Springer Nature remains neutral with regard to jurisdictional claims in published maps and institutional affiliations.

Ready to submit your research? Choose BMC and benefit from:

- fast, convenient online submission

- thorough peer review by experienced researchers in your field

- rapid publication on acceptance

- support for research data, including large and complex data types

- gold Open Access which fosters wider collaboration and increased citations

- maximum visibility for your research: over $100 \mathrm{M}$ website views per year

At BMC, research is always in progress.

Learn more biomedcentral.com/submissions 